\title{
National Climate Assessment Indicators: Background, Development, and Examples
}

Coordinating Lead Authors: Anthony C. Janetos, Robert S. Chen, Derek Arndt, Melissa A. Kenney

Contributing Authors: Daniel Abbasi, Tom Armstrong, Ann Bartuska, Maria Blair, Jim Buizer, Tom Dietz, David Easterling, Jack Kaye, Michael Kolian, Michael McGeehin, Robert O’Connor, Roger Pulwarty, Steve Running, Richard Schmalensee, Robert Webb, Jake Weltzin, Sandra Baptista, Carolyn A.F. Enquist, Jerry Hatfield, Mike Hayes, K. Bruce Jones, Chad McNutt, Walt Meier, Mark D. Schwartz, Mark Svoboda

February 2012

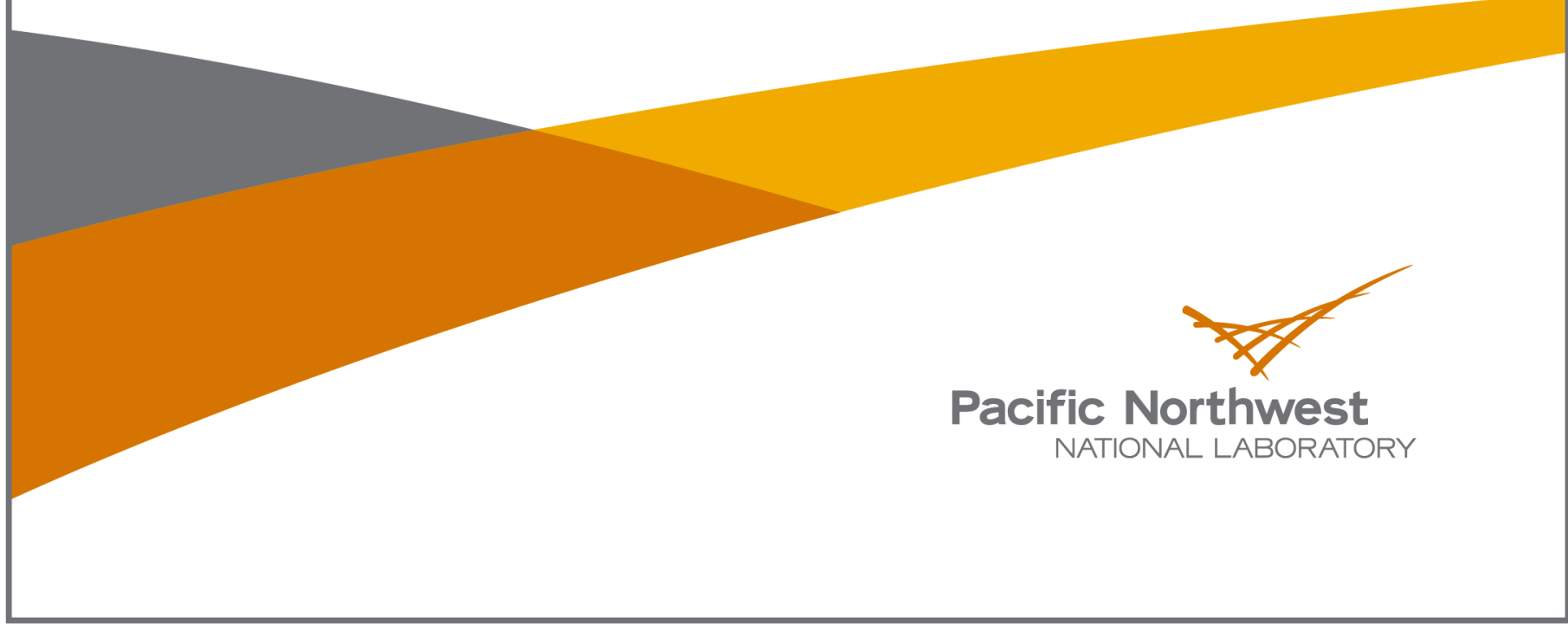




\section{Table of Contents}

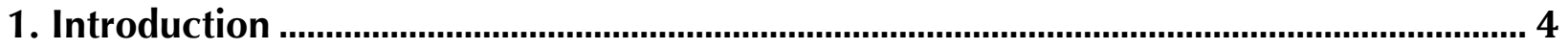

2. Purpose of Indicators for the National Climate Assessment …........................................... 5

2.1 Vision for Indicators for the National Climate Assessment .......................................................5

2.1.1 Design Criteria for the NCA Indicators ..........................................................................................

2.1.2 The Process of Establishing the NCA Indicator System ...........................................................6

2.2 Framing a System of Indicators for the National Climate Assessment Ongoing Process .......6

3. Main Lessons from the National Climate Assessment Indicator Workshops .................... 8

4. Examples of Past and Current Indicators Programs........................................................

4.1 Programs Focused on Climate-Related Issues …………........................................................9

4.1.1 National Oceanic and Atmospheric Administration Climate Indicators.................................9

4.1.2 Environmental Protection Agency's Climate Change Indicators in the United States .....11

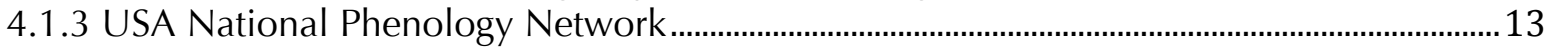

4.2 Programs Focused on Resources and Sectors of Concern ....................................................... 14

4.2.1 Heinz Center State of the Nation's Ecosystems.............................................................................15

4.2.2 National Report on the Sustainability of Forests..................................................................15

4.2.3 National Environmental Public Health Tracking Network .........................................................16

5. Underlying Research and Monitoring Programs for the National Climate Assessment

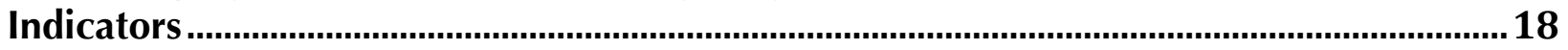

5.1 Physical Monitoring Networks and Observation Systems ....................................................... 18

5.2 Ecological Monitoring Networks and Observation Systems.................................................... 19

5.3 Societal Monitoring Networks and Observation Systems........................................................ 21

6. Examples and Discussion of Possible Questions and Indicators........................................22

6.1 Greenhouse Gas Emissions and Sinks...............................................................................2

6.1.1 U.S. Greenhouse Gas Emissions …………………….............................................................23

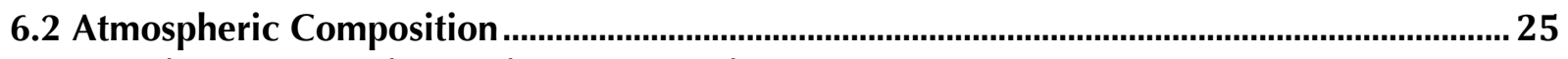

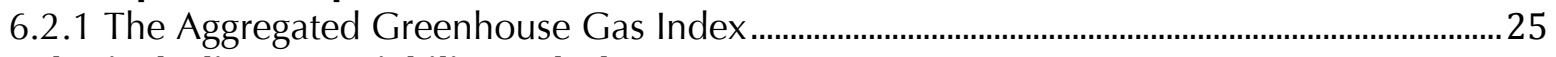

6.3 Physical Climate Variability and Change

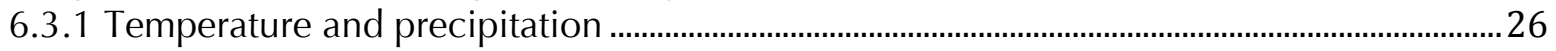

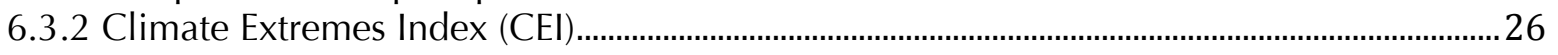

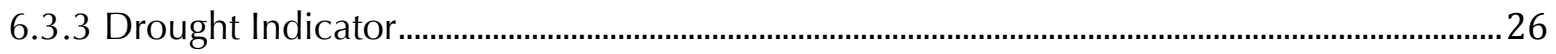

6.4 Sectors and Resources of Concern ............................................................................................ 31

6.4.1 The State of Arctic Sea Ice ........................................................................................................

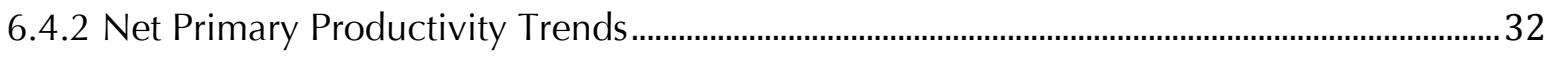

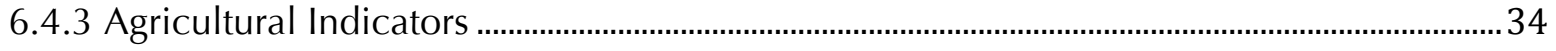

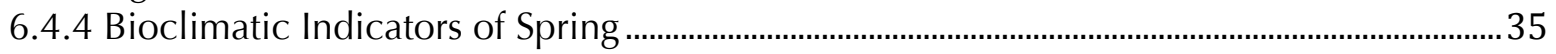

6.4.5 Heat-Related Mortality as a Climate Change Human Health Indicator ...................................36

6.4.6 Residential Energy Demand Temperature Index (REDTI). ........................................................38

6.4.7 Social Vulnerability Index..........................................................................................................38

6.5 Adaptation and Mitigation Responses ................................................................................. 39 
7. Research Agenda to Improve and Sustain the National Climate Assessment Indicator

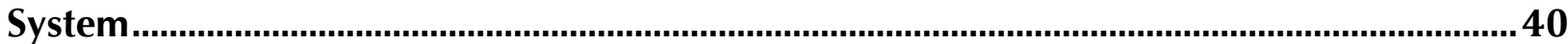

7.1 Gap Analysis.......................................................................................................................... 41

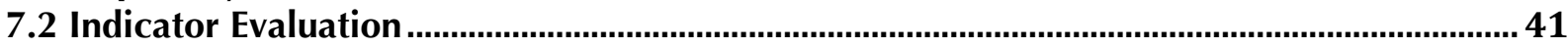

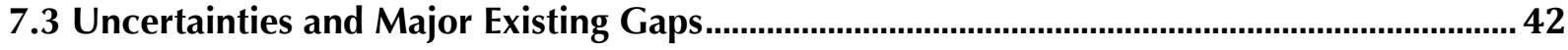

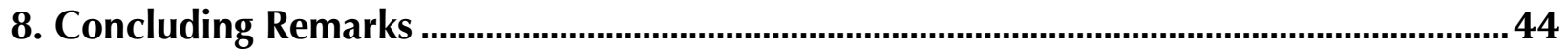

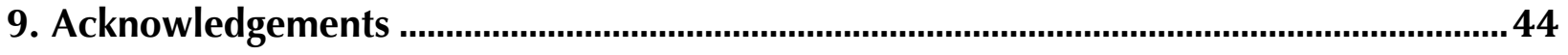

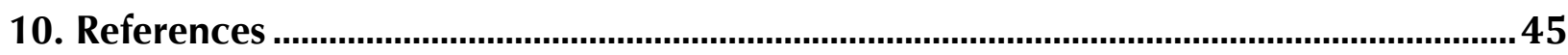

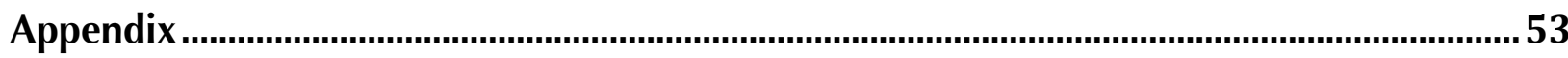

A. Examples of Federal Agency Monitoring Networks and Observation Systems .......................53

B. Examples of Federal Interagency Monitoring Networks and Observation Systems..................58

C. The Review Process for the Indicators Technical Input Report ...............................................59 


\section{Introduction}

Indicators are usually thought of as measurements or calculations that represent important features of the status, trend, or performance of a system of interest (e.g. the economy, agriculture, air quality). They are often used for the most practical of reasons - one cannot measure everything important about systems of interest, so there is a practical need to identify major features that can be reported periodically and used to guide both research and decisions (NRC 2000).

The use of indicators to track the status and trends of many features of economic performance, quality of life, and a host of other social concerns is embedded in the fabric of our everyday lives. Businesses, governments, and consumers regularly use the common economic indices - e.g. the unemployment index or consumer price index - as guides for decision-making on investments and hiring. There is an analogous demand for indicators of environmental conditions and performance - everything from agricultural yields to air and water quality to weather and climate - that are currently less publicly visible than the common economic indicators, but that can have critically important uses in such areas as natural resource management, improvement of environmental quality, emergency planning, and infrastructure development.

The National Research Council (NRC) examined this concept from the standpoint of potential ecological indicators for the nation, and concluded that indicators of status and trends would be especially useful if they could be traced back to an underlying conceptual model of how the system performs, and to questions whose answers were especially important (NRC, 2000). Many other discussions of indicators reach similar conclusions, and identify the importance of indicators being both quantitative and able to represent uncertainties in underlying information (Ayyub 2001, 2003; Ayyub and Klir 2006).

Indicators may be derived directly from data or models, or they may be dimensionless combinations of many disparate observations. They may be the products of small groups of experts or the consensus opinions of larger groups of stakeholders later refined by experts. There are many examples of all these possibilities in the literature. But regardless of the details, successful systems of indicators share certain important qualities:

- They represent a basic understanding of how a system (or some component of the system) works;

- They are quantitatively meaningful, so that they can be tracked over time, and they are able to be tied back either to measurements or models;

- Their derivation is well-documented and transparent, and the data on which they depend are also well understood with respect to their quality and heritage;

- They are able to represent uncertainties in underlying measurements and knowledge; and

- $\quad$ They are easily interpreted and useful for decision-making.

This paper establishes a rationale for developing a system of indicators for an ongoing national climate assessment process. It lays out a framework for a set of climate-related indicators that have an end-to-end character, e.g. they will provide information on greenhouse gases, variability and change in the climate system, status and trends of important sectors that are known to be sensitive to climate variability, and response strategies. Examples of potential indicators are shown in each category. These are by no means a final set of indicators, because an overall process for selection with participation from important stakeholders has not yet been undertaken. But even 
this initial set of possibilities reveals both where there is a substantial amount of well-documented information, and where there are important gaps that must be filled by subsequent research.

\section{Purpose of Indicators for the National Climate Assessment}

\subsection{Vision for Indicators for the National Climate Assessment}

The vision presented in Section 2.1 was approved by the National Climate Assessment

Development and Advisory Committee (NCADAC) at their meeting in November 2011.

Part of the vision for the sustained National Climate Assessment (NCA) process is a system of physical, ecological, and societal indicators that communicate key aspects of the physical climate, climate impacts, vulnerabilities, and preparedness for the purpose of informing both decision makers and the public with scientifically valid information that is useful for decision-making. These indicators will be tracked as a part of ongoing assessment activities, with adjustments as necessary to adapt to changing conditions and understanding. The indicators will be reviewed and updated so that the system adapts to new information.

The goals for the NCA indicators are to:

- provide meaningful, authoritative climate-relevant measures about the status, rates, and trends of key physical, ecological, and societal variables and values to inform decisions on management, research, and education at regional to national scales;

- identify climate-related conditions and impacts to help develop effective mitigation and adaptation measures; and

- provide analytical tools by which user communities can derive their own indicators for particular purposes.

\subsubsection{Design Criteria for the NCA Indicators}

The NCA indicator system will be designed to address questions important to multiple audiences including (but not limited to) non-scientists (e.g., Congress, U.S. citizens, students), resource managers, and state and municipal planners in a conceptually unified framework.

The NCA indicator system will include both current indicators and leading indicators.

- Current indicators describe current status and trends relative to a historical baseline.

- Leading indicators are used to project changes in important parameters that could result from possible climate changes.

The NCA indicators will be scalable, so that they can be presented as a national aggregate, where appropriate, and also provide information for indicators at state, regional, and local scales.

- No single scale or aggregation method needs to be imposed for all indicators.

The indicators chosen for the NCA indicator system will build on or augment existing efforts when possible.

- The NCA indicators will not replace existing, successful operational for research systems of indicators.

The NCA indicators will comply with the transparency and scientific merit guidance developed by the Knowledge Management Working Group and approved by the NCADAC. 


\subsubsection{The Process of Establishing the NCA Indicator System}

The development and deployment of the NCA indicators will engage stakeholders, both producers and users, in a two-way conversation from development to testing to implementation to evaluation.

Stakeholders will be identified from institutions that both use and produce information - for example, federal agencies, state and local government, private sector, NGOs, academic institutions.

The process of developing NCA indicators will start with important climate-relevant questions. Examples of such questions, might include:

- How do we know that climate is changing and how is climate projected to change in the future?

- What important climate impacts and opportunities are occurring or are predicted to occur in the future?

- How are we preparing for rapid change or extreme events related to climate?

- How are we adapting and mitigating over longer time frames?

- What are our fundamental vulnerabilities and resiliencies to climate variability and change?

The intent of this process is to enable users of the indicator system to address questions that are important to them about preparedness, adaptation, and mitigation.

A prototype set of indicators will be developed and discussed with stakeholders, both users and producers, to establish priorities for implementation.

The NCA indicators should be evaluated and modified as necessary.

\subsection{Framing a System of Indicators for the National Climate Assessment Ongoing}

\section{Process}

The National Climate Assessment ongoing process needs a system of indicators that are relevant to climate variability and change, their causes and consequences, and the responses to them. The indicators must also recognize, however, that while there are many consequences of climate variability and change that have been clearly documented, from the standpoint of the resources or sectors themselves, climate change is only one of many influences on their condition and trends. In addition, while the NCA has indicated that it is interested in indicators of how society chooses to respond to climate variability and change, there are no indicators that have been developed at present that are in wide use. Such indicators will need to be developed, and this will be a task for the research community.

The NCA indicator system is not intended to serve as a vehicle for documenting rigorous cause and effect relationships. It is reasonable, however, for it to serve as a guide to those factors that affect the evolution of variability and change in the climate system, the resources and sectors of concern that are affected by it, and how society chooses to respond. Different components of the end-to-end climate issue serve as categories within which to organize an end-to-end system of indicators:

- Greenhouse Gas Emissions and Sinks

- Atmospheric Composition 
- Physical Climate Variability and Change

- Sectors and Resources of Concern

- Adaptation and Mitigation Responses

These broad categories may have sub-components. For example, sectors and resource concerns should have indicators of extent, state, and system processes, but could also have indicators of sensitivity/vulnerability and/or resilience. Adaptation responses should have indicators of preparedness as well as of actual responses to climate or weather events. But the broad categories themselves identify the underlying conceptual model of the end-to-end climate issue (Figure 1).

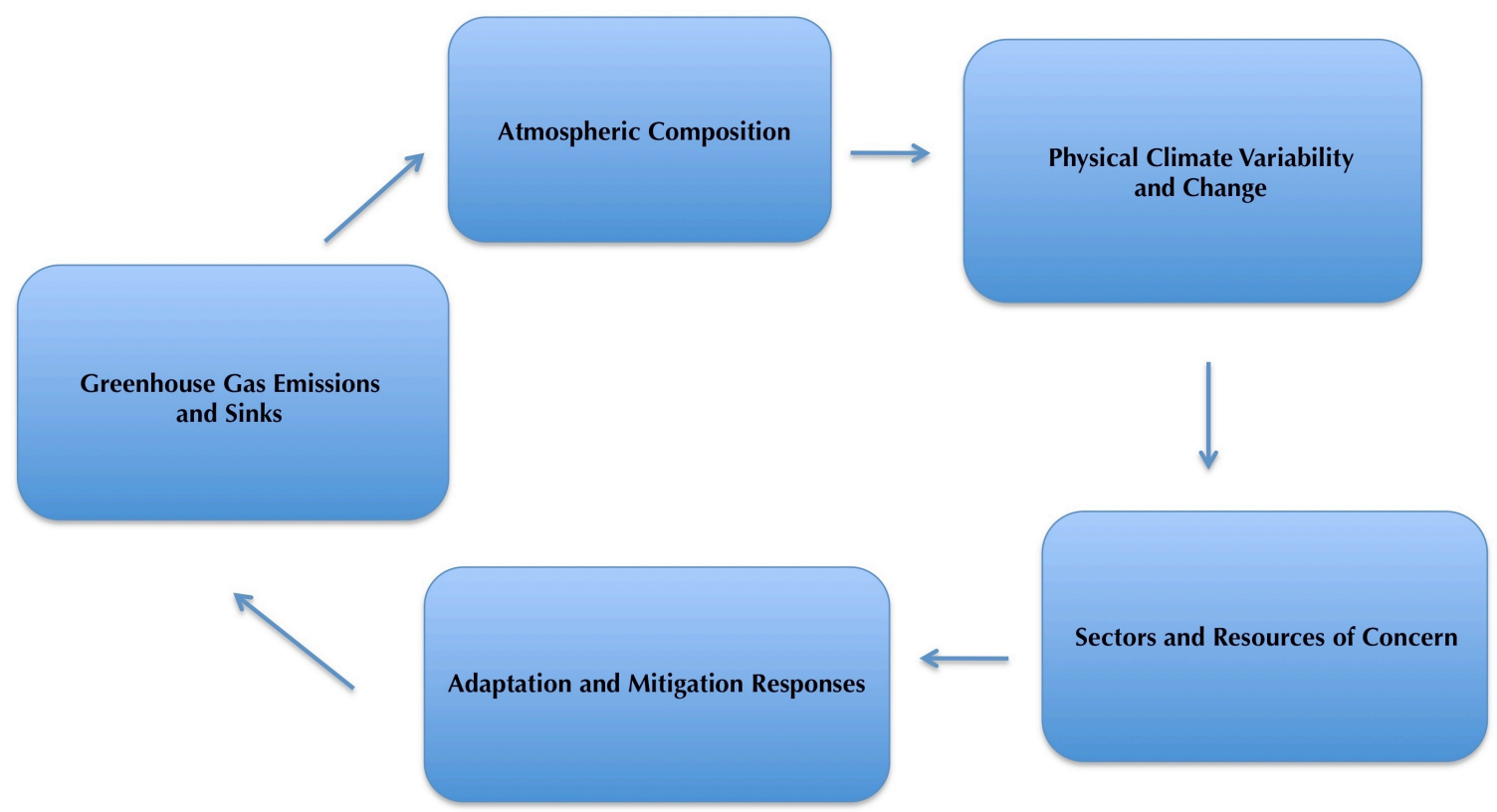

Figure 1. Categories of Indicators: Conceptual Framework for the National Climate Assessment.

This framing has several advantages. It can be used to identify the different components of the end-to-end climate issue that both decision-makers and researchers are interested in. It is independent of scale, and therefore allows the indicators themselves to be described at spatial scales that are the most relevant for their intended use. National decision-makers may find indicators of national greenhouse gas emissions to be informative; however, state or local decision-makers have the freedom in this framework to define indicators of state, regional, or local greenhouse emissions that are more relevant to their concerns. The framework is also independent of time scale and topics within the broad categories. It therefore allows indicators of different sectors to be developed, and allows the consideration of both indicators of current state, past trends, and leading indicators.

The indicators that are developed within the categories of the overall framework must be derived in an open, transparent manner, whether they are based on measurements or whether they are based on models. In part, this is because they are meant to be informative to citizens, decisionmakers, and researchers; thus, the relationship of the indicators to the underlying data and to the categories within which they fall must be clear. Uncertainties in underlying knowledge, in measurements, or in methods and models used to construct the indicators should also be clearly represented, to reduce the likelihood of misinterpretations. And the indicators should be able to 
be tracked over time, so that changes in the indicators represent real changes in the systems in their respective categories. Finally, some indicators may need to be based on methodology that conforms to U.S. participation in international data systems.

The indicators themselves may also be either representative of the current conditions of system within each category, e.g. the system's extent or its functioning, or they may be represent potential future states of the system, i.e. be leading indicators. Leading indicators may be based on measurements of the system, where such measurements provide information about future state, or they may be based on models of the system. The overall system of indicators for the NCA ongoing process is likely to include both current indicators and leading indicators, depending on the overall depth of knowledge within each category.

\section{Main Lessons from the National Climate Assessment Indicator Workshops}

The National Climate Assessment (NCA) supported three process-related workshops and discussions on ecosystem, physical, and societal indicators as part of the Third NCA process (USGCRP, 2011a, b; USGCRP, 2012). The first indicators workshop was focused on ecological systems, followed by a workshop for physical indicators, and a third on societal indicators; the later workshops benefited from lessons learned and recommendations from previous workshop. Even though the exact emphasis of the three workshops differed slightly, the goal of each of the workshops was to assist the NCA in developing a strategic framework for climate-related physical, ecological, and societal indicators that can be easily communicated with the public and other decision makers and that will support monitoring, assessment, prediction, evaluation, and decision-making.

Each of the indicator workshops had a number of recommendations that are included in the workshop reports (USGCRP, 2011a, b; USGCRP, 2012). The workshop recommendations that helped to shape the NCA indicator framework included:

- Develop an indicator system that integrates physical, ecological, and societal indicators.

- Identify the audiences that will use the NCA indicator system. The indicators cannot be everything to everyone, but can be flexible, customizable, and serve multiple audiences in a way that builds common understanding.

- The development of the NCA indicator system should start with the questions to be answered and then choose the indicators to best address the question.

- Engage stakeholders to establish the indicators to assure that there is appropriate buy-in and that the indicators are useful to the user groups.

- Leverage existing observing networks and indicators when possible. Develop the system using lessons learned from the development of other large-scale indicator systems.

- Develop indicators that are scalable from national to regional to local scales, when data are available and it is scientifically defensible to do so.

- The indicators should address the positive and negative impacts, as well as to consider drivers of climate change, vulnerabilities and preparedness.

- It is critical for the indicators to have a clear linkage to a changing and more variable climate, particularly for those indicators where climate is one of many stressors. This is especially true for ecological and social indicators. 
- Indicators developed or selected for the NCA should be scientifically defensible, meet NCA peer-review standards, and the message, approach, and data sources should be transparently presented.

- Observing systems are critical to indicators because the indicators must be developed using high quality data sources that meet the NCA guidelines. Additionally the data should have enough frequency, consistency, and coverage appropriate to their intended use.

- Communicating the indicators will require careful consideration to be understood and useful to the public.

- The indicators developed or selected for the NCA should be representative, not comprehensive (especially in the short-term).

- The indicators developed or selected for the NCA should be evaluated and adaptively managed to allow both for changes over time in the methodology and attention to over time comparability.

\section{Examples of Past and Current Indicators Programs}

There are a large number of past and current efforts aimed specifically at developing and reporting indicators for the physical climate system, natural resources, health, economic activity, and human well-being. Some, but not all of these, are relevant to climate variability and change. In fact, the indicators of the systems' responses can be related to many different stresses and forces, including changes in demand for resources, changes in management practices, changes in other environmental variables as well as changes and variability in climate.

The following examples represent some of the major efforts across the government. The examples are not meant to be comprehensive, but to represent some of the important and long-lasting indicator efforts that have characterized both scientific, resource management, and health agencies. Programs that are focused on climate and climate change related indicators are discussed first, followed by programs that focus on the resources or sectors themselves, independent of climate change.

\subsection{Programs Focused on Climate-Related Issues}

The National Oceanic and Atmospheric Administration (NOAA), Environmental Protection Agency (EPA), and U.S. Geological Survey (USGS) have active indicator programs that are specifically designed to address climate-related issues. For NOAA, there is a strong focus on the physical climate system, including changing atmospheric composition and radiative forcing, and changes and variability in the climate system itself. For EPA, there is also a focus on some atmospheric quantities, but in addition, there is a strong focus on potential impacts and changes in natural resources that are known to be influenced by climate variability and change. The USGS program on phenological change has created indicators of one particular marker of change in ecosystems that is known to be influenced by variability in physical climate.

\subsubsection{National Oceanic and Atmospheric Administration Climate Indicators}

To support its mission, the NOAA constructs a large number of indicators that focus primarily on the changes in the physical climate system, and in particular, the oceans and atmosphere. These indicators have different uses within the agency. For example, much of the understanding and development of certain El Niño / Southern Oscillation (ENSO) indicators were developed at NOAA's Climate Prediction Center, which uses them as diagnostic tools to support climate 
prediction on seasonal to inter-annual and longer time scales. These same indicators are employed at the National Climatic Data Center (NCDC) to partially explain year-to-year variance in the globally-averaged surface temperature, which is itself another climate indicator. ENSO indicators are known to be correlated with sea level in the equatorial Pacific basin and seasonal weather outcomes in and around the basin.

NOAA conducted an internal survey of its climate monitoring activities in October 2010. In addition to the National Weather Service, which operates most of the weather station networks that inform the nation's climate record, at least twelve organizations are actively performing climate monitoring. These efforts often include the construction of indicators. The report from that survey is available at: http://www.cpo.noaa.gov/news/2011/CMS_Report_01_11_2011-1.pdf. The following sections present several indicators in NOAA's portfolio of indicators.

\subsubsection{Atmospheric Composition Indicators}

For several decades, NOAA's Earth Systems Research Laboratory (ESRL) has observed, compiled and analyzed data about climatically important constituents such as trace gases and aerosols. ESRL's approach emphasizes observing and monitoring constituents and processes through the depth of the atmosphere. Among other benefits, these efforts contribute to a further understanding of the evolving concentrations, isotopic compositions, state, trend, and variability of the major and minor trace gases.

\subsubsection{The State of the Climate Report}

Since 1991, NOAA has coordinated the construction, review and publication of a yearly report assessing the status of the climate system. This effort is now a peer-reviewed annual supplement to the Bulletin of the American Meteorological Society and is known as the State of the Climate report (http://www.ncdc.noaa.gov/bams-state-of-the-climate/). It aims to describe, as fully as possible, the status, variability, recent behavior, and trend (if appropriate) of the various physical components (state variables and phenomena) across the vast breadth of the climate system. The State of the Climate in 2010 was created and written by 368 scientists from academic institutions and mission agencies in 45 countries.

Although the host journal is meteorological in nature, the variables and phenomena reported address a comprehensive swath of the physical climate system. The report pursues a complete assessment of each of the Essential Climate Variables (ECVs) as defined and maintained by the climate observing community through the Global Climate Observing System (GCOS, 2010). The State of the Climate in 2010 fully or partially covered 41 of the 50 ECVs (Table 1). Like the authorship, the constituent datasets that address the ECVs come from a variety of academic and mission-based efforts. 
TABLE 1. Essential Climate Variables defined by the Global Climate Observing System.

Atmospheric Surface: Air temperature, wind speed and direction, water vapor, air pressure, precipitation, surface radiation budget.

Atmospheric Composition: Carbon dioxide, methane, other long-lived gases (nitrous oxide, chlorofluorocarbons, hydrochlorofluorocarbons, hydrofluorocarbons, sulphur hexafluorides, perfluorocarbons), ozone, aerosols.

Ocean Subsurface: Temperature, salinity, current, nutrients, carbon dioxide partial pressure, ocean acidity, oxygen, tracers.
Atmospheric Upper Air: Temperature, wind speed and direction, water vapor, cloud properties, earth radiation budget.

Ocean Surface: Sea-surface temperature, sea-surface salinity, sea level, sea state, sea ice, surface current, ocean color, carbon dioxide partial pressure, ocean acidity, phytoplankton.

Terrestrial: River discharge, water use, land cover, snow cover, groundwater, glaciers and ice caps, lakes, ice sheets, permafrost, albedo, leaf area index, above-ground biomass, fraction of absorbed photosynthetically active radiation, soil carbon, fire disturbance, soil moisture.

\subsubsection{Climate Monitoring by the National Climatic Data Center}

NOAA's climate monitoring portfolio extends across the agency. This section highlights monitoring activities at its NCDC. As part of its monitoring mission, NCDC maintains a large suite of datasets and related indices. There are currently about 60 families of indicators being actively monitored at NCDC. Selected examples are given below. The complete list of monitoring products is available at http://www.ncdc.noaa.gov/climate-monitoring/inventory.php.

The indicators cover a spectrum of purposes, complexity, and sophistication (Table 1), from physical variables (such as temperature, precipitation or wind speed), to specific applications such as the Residential Energy Demand Temperature Index, to more complex aggregations of multiple factors such as the Climate Extremes Index.

Individual indicators each have their own presentation and update cycle, but a monthly time-step is very common for updating, analysis and reporting. Many are compiled into monthly plainlanguage reports. Most are presented publicly through NCDC's Climate Monitoring Branch, but the underlying science and data is a shared responsibility across NCDC. The indices are shared publicly with supporting information about processes, methods and scientific background. They are also assimilated into broader indicators efforts such as those run by the Environmental Protection Agency (Section 4.1.2) and the World Meteorological Organization.

\subsubsection{Environmental Protection Agency's Climate Change Indicators in the United States} The EPA summarizes information on indicators related to climate change in its 2010 report Climate Change Indicators in the United States report. The report presents 24 indicators to help 
readers better understand observed trends related to the causes and effects of climate change (Table 2). The indicators reflect a range of time-periods and focus primarily on the United States, but in some cases global trends are provided for context or a basis for comparison. The set of indicators include several fundamental measures of climate and are grouped into five topical chapters (Table 2).

TABLE 2. Summary of Environmental Protection Agency Climate Change Indicators.

Greenhouse Gases: U.S. Greenhouse Gas Emissions, Global Greenhouse Gas Emissions, Atmospheric Concentrations of Greenhouse Gases, Climate Forcing

Oceans: Ocean Heat, Sea Surface Temperature, Sea Level, Ocean Acidity

Society and Ecosystems: Heat-Related Deaths, Length of Growing Season, Plant Hardiness Zones, Leaf and Bloom Dates, Bird Wintering Ranges
Weather and Climate: U.S. and Global Temperature, Heat Waves, U.S. and Global Precipitation, Heavy Precipitation, Drought, Tropical Cyclone Intensity

Snow and Ice: Arctic Sea Ice, Glaciers, Lake Ice, Snow Cover, Snowpack

\subsubsection{Background}

EPA has a long history of developing and using indicators across several Agency programs. EPA has been working on climate change indicators since 2002 to support EPA's Report on the Environment (ROE) and in partnership with EPA's Office of Research and Development (ORD) and other agencies.

The core purpose of the report is to communicate the multiple lines of evidence to inform readers' understanding of climate change. In addition to presenting climate change observations and trends in the U.S. and globally, this report highlights the far-reaching significance of these changes and their possible consequences for people, the environment, and society.

This report is also useful for scientists, analysts, decision makers, educators, and others who can use climate change indicators as a tool for:

- assessing trends in environmental quality, factors that influence the environment, and effects on ecosystems and society;

- effectively supporting science-based decision-making and communication; and

- evaluating existing and future climate-related programs.

\subsubsection{Approach}

Various government agencies, academic institutions, and other organizations contribute data critical to the development of the indicators. All of the indicators in this report are based on peerreviewed data that have been collected and compiled according to protocols accepted by the scientific community. The indicators were chosen using a standard set of criteria that considered usefulness, objectivity, data quality, transparency, ability to meaningfully communicate, and relevance to climate change. 
Each indicator features five elements: (1) one or more graphics depicting changes in the indicator over time, (2) key points about what the indicator shows, (3) background on how the indicator relates to climate change, (4) information about how the indicator was developed, and (5) factors that influence one's ability to draw valid conclusions from the indicator.

Accompanying the report is a technical support document which describes detailed information about each indicator, including data sources, data collection methods, calculations, and statistical considerations. This document also describes EPA's approach and criteria for selecting indicators for the report (www.epa.gov/climatechange/science/indicators).

\subsubsection{USA National Phenology Network}

The USA National Phenology Network (USA-NPN; www.usanpn.org), established in 2007 as a partnership-driven program with leadership by the USGS and with funding from the National Science Foundation, USGS, and several other organizations, is a national science and monitoring network that organizes and facilitates the collection and integration of phenological observations across space and time (Jones et al., 2010). Partners include scientists, resource managers, educators, and policy-makers from a diversity of organizations including governmental and nongovernmental organizations, American Indian tribes, specialized networks, and academic institutions.

The primary goals of the USA-NPN are to (1) understand how plants, animals and landscapes respond to environmental variation and climate change, (2) develop tools and techniques to facilitate decision making and, ultimately, climate change adaptation by humans and natural systems, and (3) use experiential learning to engage and educate the U.S. public by involving them in the process of place-based science in the natural world. The USA-NPN meets these goals through the development of information management systems, creation of partnerships, facilitation of research, development of decision-support systems, and promotion and implementation of education and outreach activities (Schwartz et al., 2012).

An essential activity of the USA-NPN is the collection and organization of contemporary phenology data for plant and animal species across the nation. Since 2007, the USA-NPN has focused on the development of a national biological observation program with scientifically rigorous monitoring protocols for over 500 plant and animal species. USA-NPN partnered with NatureServe and The Wildlife Society to develop and vet criteria for selection and prioritization of the initial species list, including known or presumed sensitivity to climate change.

In addition, the USA-NPN has partnered with several science and monitoring programs (e.g., National Ecological Observatory Network, Long-term Ecological Research Network (LTER), National Park Service (NPS)) to develop, vet, and test standardized monitoring protocols for observing species (Thomas et al., 2010). Contemporary protocols were designed to be concordant with existing and historic phenology observation programs and protocols where possible. The data generated using these protocols can be combined with climatological data to generate phenologyrelevant climate indices, such as the Spring Indices (Schwartz et al. 2006). These can be used to investigate ecological responses to climate change across multiple scales.

Standardized phenology monitoring protocols, documentation, and an on-line user interface for data entry, visualization, and download are now available as part of the USA-NPN program Nature's Notebook (Figure 2). Data from Nature's Notebook are being used to develop new 
indicators of onset of spring, validate remote imagery, model the probability of western wildfires, predict the onset of allergy seasons, plan management of invasive species, inform adaptive management, and establish baselines for ecosystem restoration. In addition, the national monitoring framework provided by the USA-NPN is being adopted by a variety of organizations (e.g., NPS, USFWS, NEON) as a fully operational platform for mission-based programs or projects related to science, resource management, information technology, and education/outreach activities (Schwartz et al., 2012). It will be important to carefully define and document quality assurance/quality control volunteer-based networks such as USA-NPN and the Breeding Bird Survey (BBS): typically, the number of measurements is said to compensate for the likely variability in measurement accuracy at any one site, in contrast with more tightly defined formal in-situ observation networks. Research on the comparison and integration of these sources of data is recommended to understand and minimize error in indicator assessments.

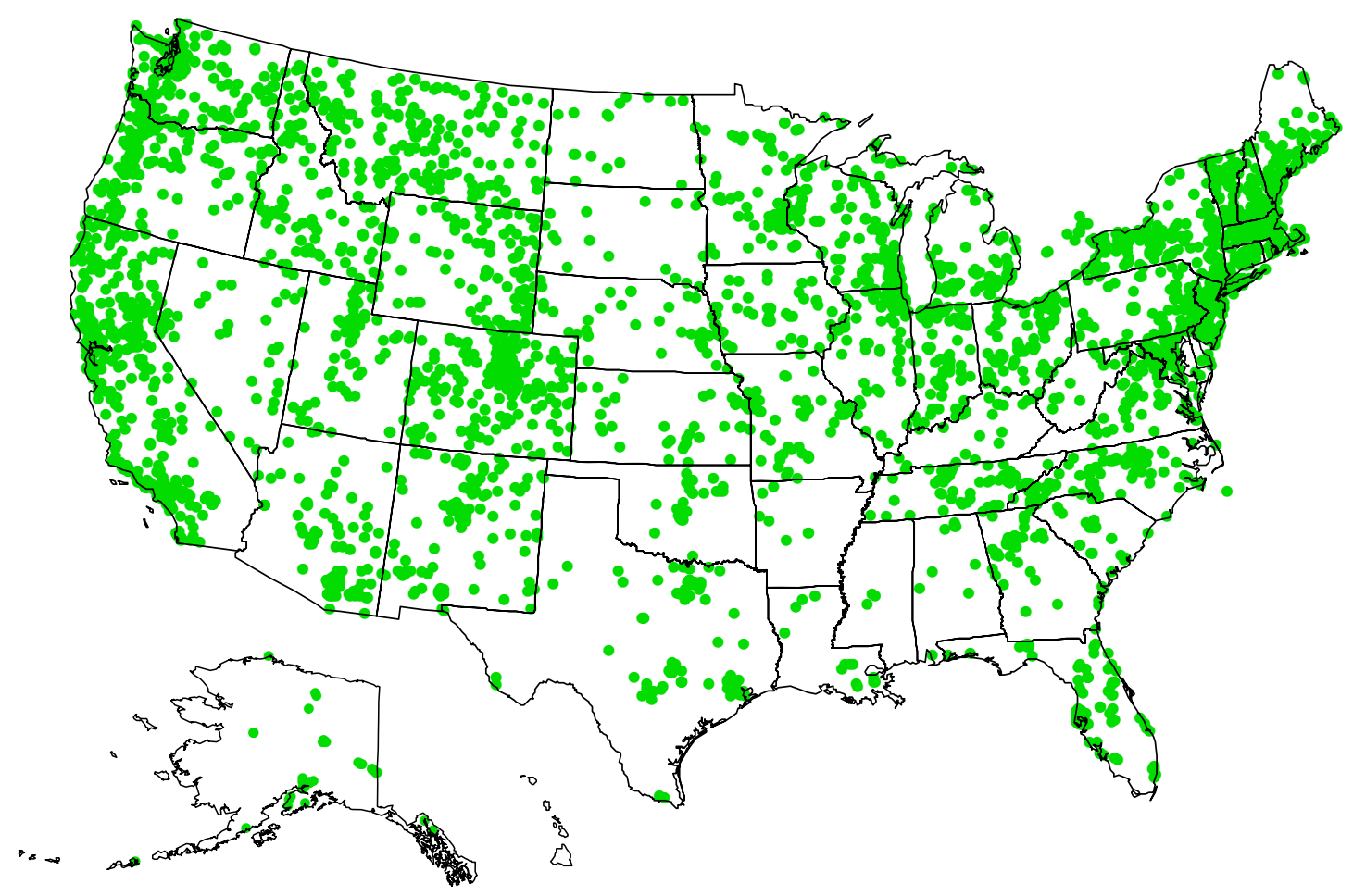

Figure 2. USA National Phenology Network. The USA National Phenology Network has developed a multi-taxa phenology monitoring program, Nature's Notebook, which has $\sim 4,000$ registrants at $\sim 5,000$ sites (green dots on figure) tracking $\sim 16,000$ organisms across the nation as of January 2012. These sites include those maintained by members of the public (as individuals or organizations including nature preserves, schools and clubs, and neighborhood associations), as well as governmental and non-governmental organizations charged with science or management of natural resources.

\subsection{Programs Focused on Resources and Sectors of Concern}

These programs, including the Heinz Center's efforts on ecosystem indicators, the Forest Service's efforts on sustainability indicators, and CDC's environmental health indicators, are not focused 
specifically on climate change-related issues. Instead, they focus on the resources or sectors of concerns themselves, regardless of the source of the changes.

\subsubsection{Heinz Center State of the Nation's Ecosystems}

The H. John Heinz III Center for Science, Economics, and the Environment hosted a decade long effort to identify and report on ecological indicators for the U.S. (Heinz Center 2002; Heinz Center, 2004; Heinz Center, 2006; Heinz Center, 2008a,b,c; Heinz Center, 2010). The effort developed from a desire in the to ensure that there was a systematic effort to report on indicators of the status, trends, and important features of a wide variety of U.S. ecosystems: forests, farmlands, freshwater resources, coasts and oceans, grasslands and shrublands, and urban and suburban areas.

Indicators for each target ecosystem were developed through a lengthy process of consensus building among stakeholder communities that included representatives from government, nongovernmental organizations, universities, and the private sector. Working groups were charged to identify features of these ecosystems that were felt to be particularly important to track for decision-making purposes, and then to develop indicators of changes in those features. Final lists of indicators were down-selected to a manageable number for each ecosystem. Indicators were then selected for initial reporting based on the availability of data for national reporting (Heinz Center, 2002). Indicators without sufficient data for national reporting were specifically used to identify data gaps and a second report (Heinz Center, 2004) was issued. This report was carefully coordinated with federal agencies that have responsibilities for the underlying measurement programs on which the Heinz Center indicators were based.

There were also indicators on which the stakeholder groups did not reach consensus in the first report, but for which consultations and research continued to be done. For example, an indicator on habitat fragmentation in forests was not included in the first report, but additional discussions among the working group assigned to forest ecosystems created agreement by the time of the second major report $(2008 \mathrm{~b}, \mathrm{c})$. Thus, the indicators themselves continued to evolve over time.

There were two national reports on the Heinz Ecosystem Indicators (2002, 2008a), but the indicators were updated on a website when new data was available from the federal agencies. Continual oversight from a steering committee of representatives from the agencies, nongovernmental organizations, the private sector, and universities was used to ensure that the set of indicators could evolve over time, to ensure that they were responsive to the needs of stakeholders, and to provide feedback on the utility of the indicators from people who used them in various ways.

\subsubsection{National Report on the Sustainability of Forests}

In 2003, the first National Report on Sustainable Forests reported on the state of forests in the U.S. and the indicators of national progress toward the goal of sustainable forest management. The indicators reflect the biophysical, economic, and societal aspects of sustainability. It also provided examples of current actions and identified challenges to assessing the sustainability of forests. That report is prepared to fulfill one of the U.S.' commitments to the Montréal Process Working Group on Criteria and Indicators for the Conservation and Sustainable Management of Temperate and Boreal Forests (MP C\&l; http://www.mpci.org). Membership in the Working Group is voluntary and currently includes 12 countries from both hemispheres covering a wide range in ecological and social conditions. The member countries represent about 90 percent of the world's temperate 
and boreal forests in the northern and southern hemispheres, amounting to 60 percent of all of the forests of the world.

An updated report is expected in 2012. In addition to new data for the indicators, the process for updating incorporates feedback to the 2003 report; in this way, the National Report on Sustainable Forests is a living document. Specific changes include:

- increased emphasis on electronic, web-based reports rather than paper copies;

- more data and interpretations at the sub-national level; and

- data on the tropical forests of the U.S. in addition to the Nation's temperate and boreal forests.

Consisting of seven criteria and 64 indicators, the MP C\&I have undergone extensive scrutiny over the past decade by both the scientific community as well as practitioners from international to local scales. The updated report will include new indicators that reflect new scientific understanding as well as knowledge about the practicability of the indicators. This framework provides organization to the numerous data sources and scientific efforts underway attempting to measure the state of our Nation's forests. Thus, individual indicators provide insight into specific criteria, in turn, when the seven criteria are considered as a whole, they provide a yardstick from which society can measure its progress towards sustainability goals.

These criteria are used by a range of organizations. Notably, the criteria are used by United Nations Food and Agriculture Organization as the organizing framework for their 2010 Global Forest Resource Assessment. The U.S. Forest Service and the state forestry organizations in the 20 northeastern states have established a Forest Sustainability Indicators Information System to track trends in forest health and sustainability. Additionally, the MP C\&I are used as a framework for assessing progress in achieving sustainable forest management; for example, Baltimore County, Maryland, is using the MP C\&I to envision desired future conditions, engage citizens in dialogue, and set goals.

\subsubsection{National Environmental Public Health Tracking Network}

The National Environmental Public Health Tracing Network (EPHT) is an integrated, multi-state system providing on-going collection, integration, and dissemination of data from environmental hazards monitoring, human exposure tracking, and health effects surveillance (McGeehin, et al., 2004). The data from EPHT enable public health authorities to determine disease impacts and trends, recognize disease clusters and outbreaks, identify populations most affected by diseases or exposures, and assess the effectiveness of public health interventions (Teutsch, 2000). This surveillance system is funded and coordinated by the Centers for Disease Control and Prevention (CDC) and currently includes 23 states and New York City. EPHT is a distributed, secure, webbased system providing access to data collected by multiple health and environment agencies (Figure 3). All data included and displayed in the system must meet nationally consistent data and measure standards and guidelines established by $\mathrm{CDC}^{\prime}$ s Public Health Information Network. 


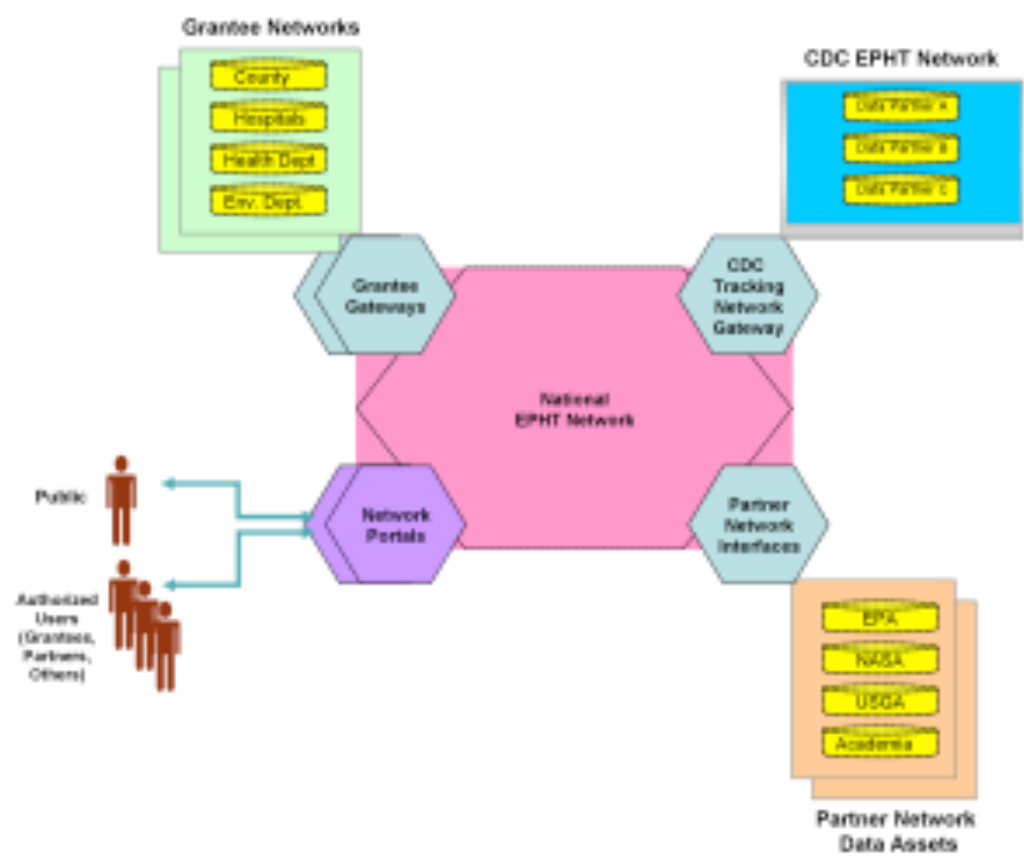

Figure 3. Overview of the National Environmental Public Health Tracking Network. Source: Centers for Disease Control and Prevention, 2006. National Environmental Public Health Tracking Program: National Network Implementation Plan: pg. 5.

A key benefit of EPHT is to provide public access to local, state, and national databases of standardized metrics for environmental hazards and human health effects. The nationally consistent databases included in EPHT were recommended by the EPHT Content Workgroup comprised of scientific staff from agencies included in the EPHT and other interested organizations. Measures were included in the EPHT based on a number of criteria including whether the data were easily available at a statewide level and the public health importance of the health effect or environmental hazard, among others.

The indicators and measures of EPHT are available to the public user through an interactive website. The data are displayed in two general categories: environment and health effects. These categories are further divided into familiar topic areas, such as outdoor air, community water, birth defects, and asthma. The site visitor can search to find scientifically valid information on the subject, including possible links between the environment and human health. The user can also search the topic by geographic area and specific name of the indicator and measure to see data displayed by map, table, or graph (for example, age-adjusted rate of chronic lymphocytic leukemia for Colorado for 2008 or annual modeled PM 2.5 levels for counties in Alabama for 2006). More detailed information and the source databases are available to researchers through a second, secure website.

In 2011, EPHT introduced a suite of indicators to track the effects of climate change. These measures were developed by an expert, scientific team with experience in health surveillance, environmental monitoring, and climate change impacts. The EPHT website provides access to climate change data on multiple measures for three indicators focused on extreme heat: heat vulnerabilities, heat-related mortality, and temperature distribution. Multiple measures are 
available for each of these indicators. The heat vulnerability indicator is comprised of 10 measures associated with increased risk of heat mortality ranging from county level of diabetes to percent of developed land use. The site also includes the derivation of each of the measures with links to the source data. As with all EPHT data, the users can search by geographic area, measure, and year to see data displayed in multiple formats. The National EPHT Network is an excellent example of a government-sponsored system that provides complex scientific data to the public in a user friendly, understandable format.

\section{Underlying Research and Monitoring Programs for the National Climate Assessment Indicators}

Indicator programs are critically dependent on the availability and reliability of high-quality data on the systems of concern. These are often produced specifically by ongoing operational monitoring programs, or by long-term research networks. Examples (i.e., not a comprehensive list) of such underlying observational platforms are provided in this section and in Appendices $A$ and B. These provide much of the data used in the indicator efforts outlined in the previous section, and highlight the importance of the interplay between observations and the development and reporting of indicators.

\subsection{Physical Monitoring Networks and Observation Systems}

Indicators of the physical climate system can often be categorized in one of two categories: longterm measurement of a state variable or fundamental process (like temperature or precipitation), or observation of important phenomena that have some sort of definition (like heat waves or hurricanes). In either case, the underlying data on which indicators are built depend heavily - and often completely - on the ongoing operation and support of observing networks and platforms. In any of the climate system's major physical subcomponents (atmosphere, cryosphere, hydrosphere, lithosphere) observations come from some combination of operational monitoring systems (surface-based or satellite-borne), long-term research efforts, or systematic collection of information from systematic expeditionary efforts such as cruises or field campaigns.

A sample of this distributed responsibility can be seen in the collective effort to monitor weather and hydrology by U.S. institutions alone. Surface weather-type variables at the surface and in the atmosphere are drawn from a combination of automated and manned weather stations, radiosonde (weather balloon) fleets and satellites. The vast majority of these are commissioned as operational by Federal Agencies to support weather and hydrology missions. Their climate value comes in their subsequent development into a consistent long-term record. Examples of physical monitoring systems of this type include the U.S. Historical Climatology Network and the USGS stream gage network. Relatively few observing systems explicitly incorporate in their design the goal of explicitly capturing climate-scale variability and change; examples include the surfacebased Climate Reference Network (Vose et al., 2005) and the Suomi Net Primary Productivity (NPP) satellite mission. Purposeful long-term observation of trace gases and of the upper atmosphere is performed by a relatively small number of research labs and academic institutions. The observing networks established have much smaller and coarser spatial coverage, and continuity of record is vital to the establishment and maintenance of indicators. 
An analogous situation occurs in the oceans, where observations by buoys and ships-at-sea serve shorter-term missions (weather and shipping), but contribute to climate understanding through the value of their long-term record. As in the weather and hydrology arena, satellite observation of the oceans provides broad and comprehensive spatial coverage not attainable through in situ observation alone. Other purposefully-observed conditions, especially at depth from the surface, come from scientific voyages or fleets of unmanned roving vessels. Observations of the state, trend, and characteristics in the cryosphere are proportionally more dependent on the research community, and long-term automated observations, even of weather, are scarce and invaluable. Expeditionary data collection is often the mechanism on which understanding is built.

Despite coming from a diverse array of originating institutions and observing platforms, the data generated by the above efforts becomes valuable to indicators only after they have been collected, preserved, and made ready for incorporation. Understanding and incorporating the evolution of observing configurations (e.g., station locations, instrumentation type, commissioning / decommissioning of platforms) into climate-quality datasets is an ongoing activity both within and between surface-based systems (e.g., homogeneity adjustments as in Menne \& Williams, 2009) and satellite-based records (e.g, Climate Data Records as in NRC, 2004).

\subsection{Ecological Monitoring Networks and Observation Systems}

There are a number of observing networks across the nation already devoted to tracking biodiversity, ecosystems, and/or ecosystem services (USGCRP 2011a; OSTP, 2012; USGS 2012). Most in situ research and monitoring systems are limited to specific areas for specific purposes, e.g., to understand biogeochemical fluxes within a small watershed, or because of costs and consistencies related to implementation across broader spatial scales. However, many of our most pressing questions and environmental challenges can only be solved by understanding processes and interrelationships across many temporal and spatial scales. The interagency Committee on the Environment and Natural Resources (CERN) suggests conceptual organization of ecological research and monitoring into three interrelated tiers to facilitate ecological understanding across scales: intensive research sites, widely distributed in-situ monitoring sites, and spatially extensive remote sensing data (Figure 4; CENR, 1997).

Intensive research and monitoring systems provide site-based research at spatial and temporal scales appropriate for intensive data collection on ecological processes including fluxes and flows of biota, energy, water, and materials and nutrients. Established national networks of intensive research sites include: Ameriflux, which tracks ecosystem gas exchange, vegetation and canopy attributes and provides for associated process-based research; the Long-Term Ecological Research (LTER) program comprised of terrestrial and marine sites that represent different biophysical settings and ecoregions in managed and natural ecosystems; and the National Ecological Observatory Network (NEON), a developing continental-scale research platform for understanding the impacts of climate change, land-use change, and invasive species on ecological systems. 


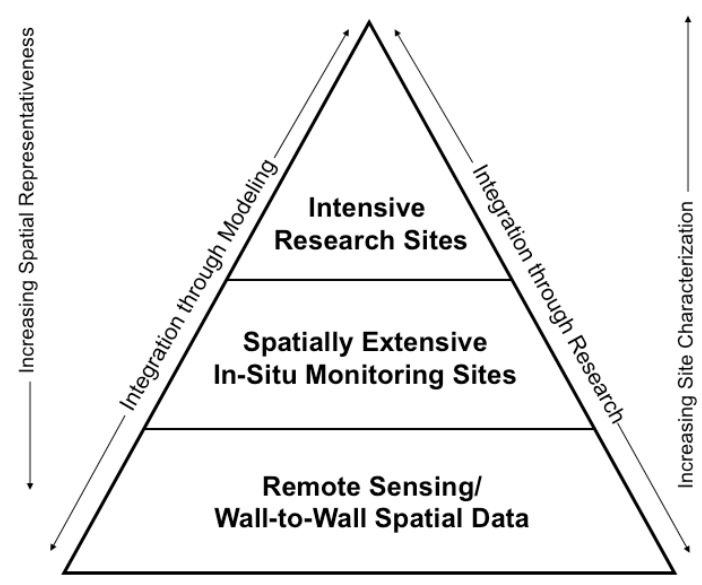

Figure 4. The Committee on Natural Resources and the Environment (CENR) multi-tiered monitoring framework (modified from CENR, 1997 by Jones et al., 2010).

Spatially extensive in situ monitoring networks can contribute substantially to an understanding of site and landscape-scale ecological changes over broad geographic areas, including regional, national, and continental scales, facilitate the development of empirical/statistical models about the responses of processes and resources, and enable validation of process models. Examples of spatial extensive science networks that collect ecological data include the National Water-Quality Assessment Program (NAWQA), the Department of Interior (particularly NPS, USFWS, and BLM) Assessment, Inventory and Monitoring Networks, the USDA Forest Inventory and Analysis Program (FIA), and the USGS stream gage network which tracks stream and river flow across the U.S. Spatially extensive and well-organized volunteer-based observational networks (e.g., Breeding Bird Survey) also provide critical observational data for understanding change and processes across scales (Sagarin and Pouchard 2009). Deterministically-selected sites for in-situ monitoring are complemented by probability-based surveys used to map condition directly (e.g. the EPA stream and lake survey and the USFS Forest Inventory and Analysis program).

The diversity and availability of spatially extensive remote sensing data have increased greatly over the last two decades, and have greatly facilitated land surface and ecological assessments over broad areas. Common low-resolution platforms such as the Advanced Very High-Resolution Radiometer (AVHRR) and the Moderate-resolution Imaging Spectroradiometer (MODIS) provide important vegetation indices and biophysical features on a global scale. Moderate-resolution imagery provided by Landsat and the Advanced Spaceborne Thermal Emission and Reflection Radiometer (ASTER) have been used extensively to monitor earth surface conditions and change, whereas high-resolution spatial data generated from satellites such as IKONOS and Quickbird, and from high-resolution aerial photography, such as that generated from the National Agricultural Imaging Program (NAIP), provide detailed information on fine-scale landscape features. Unlike high-resolution data from commercial satellites, NAIP provides 1-meter resolution data for the most of the conterminous U.S. and is collected every two years and can be downloaded for free.

Each of these established monitoring frameworks are strongly science-based, set the standard for replicable monitoring across scales, provide traceability of data and information, and can be reprocessed or modified as knowledge and/or algorithms improve. An ongoing challenge is the integration of information across disparate and multidisciplinary sources, and across spatial and temporal scales. Nonetheless, the multi-tiered monitoring approach advocated by CENR (1997), 
and that is already in place within some programs and projects (Jones et al. 2010; see also Section 4.1.3 on USA National Phenology Network as a multi-tier network), provides a conceptual framework to integrate ecological, physical and societal science-based observation and monitoring programs across scales in support of the NCA.

\subsection{Societal Monitoring Networks and Observation Systems}

As in the case of the physical and ecological monitoring networks and systems described above, monitoring and observation of economic and social trends are often based on the collection of data for other purposes, in this case administrative and planning needs. One of the longest running data collection efforts in the U.S. is the decennial census, which dates back to 1790 when Congress first called for a count of free white males and females, all other free persons, and slaves in the original 13 States and other selected districts and territories. Over time, additional questions and categories were gradually added to the census to inform planning and decision-making related to mining, agriculture, commerce, manufacturing, education, transportation, and other topics. The introduction of an electric tabulating system developed by Herman Hollerith in the 1890 census enabled expansion of the range of questions for a growing population, including more details about race, ethnicity, housing, military service, and other social data. Beginning in 1940, the census began using probability sampling methods to enable collection of additional data on income, housing, employment, unemployment, and migration, reflecting concerns stemming from the Great Depression. The 1960 census introduced the "long form," a more detailed questionnaire for about one quarter of occupied housing units. The Census Bureau's long standing Current Population Survey and, more recently, the American Community Survey, are continuous measurement programs designed to provide the public with data on population, labor force, and housing important for planning investments and services (U.S. Census Bureau, 2012).

Many other Federal agencies collect important administrative data and, in turn, produce key societal indicators widely used in national, regional, and local decision making, both by the public and private sectors. For example, the Bureau of Economic Analysis (BEA) manages the U.S. economic accounts, producing indicators such as the Gross Domestic Product (GDP), personal income, and the trade deficit (BEA, 2012). The Bureau of Labor Statistics (BLS) tracks employment, unemployment, labor productivity, consumer expenditures, and prices and inflation, including details by state, industry, month and year, and other dimensions, and issues indicators such as the Consumer Price Index (CPI), which is based on a scientifically selected sample of consumer prices collected every month (BLS, 2012). Similarly, in the arena of public health, the Centers for Disease Control and Prevention (CDC) maintains the National Vital Statistics System, which collects standardized data on mortality and births, and conducts a range of regular surveys on health, nutrition, health care, immunization, and other topics (CDC, 2012). Other agencies such as the Departments of Energy and Transportation collect data and produce indicators on important issues in their mission areas, e.g., on energy production, use, and efficiency.

Outside of the Federal government, there are also other important sources of societal data and indicators. The General Social Survey, funded by the National Science Foundation has collected data on the structure and development of American society since 1972 and is considered the most frequently analyzed source of information in the social sciences other than the U.S. Census (General Social Survey, 2012). The American National Election Study has been generating data sets available to the research community since 1948. The Inter-University Consortium for Political and Social Research (ICPSR) archives thousands of social science data sets that are readily available to the research community. The Roper Center for Public Opinion Research (2012) 
provides access to data thousands of public opinion and exit polls from around the world, including responses to questions about environmental management, global warming, and other climate-related topics. However, while the social science community has a long history of developing and sharing social indicator data sets, there has to date been no dedicated effort to develop such a resource focused on societal aspects of environment and climate change (NRC, 2010a).

The development of new monitoring networks and observational systems for societal phenomena and trends related to climate is still in its infancy. For example, operational observations of lights at night have been collected by Defense Meteorological Satellite Program (DMSP) since 1992 and processed into consistent datasets on human residence and activity (e.g., fishing, natural gas flares) at global scales (NOAA NGDC, 2012). These data have been used as inputs into coarse-resolution, global indicators of urban extent, the human "footprint", poverty, economic growth, and other societal issues of interest (Sanderson et al. 2002; Henderson et al., 2011; Balk et al., 2006; Doll, 2008).

\section{Examples and Discussion of Possible Questions and Indicators}

The framework introduced in Section 2 provides a structure within which to consider specific indicators for the National Climate Assessment. The framework identifies five categories:

- Greenhouse Gas Emissions and Sinks

- Atmospheric Composition

- Physical Climate Variability and Change

- Sectors and Resources of Concern

- Adaptation and Mitigation Responses.

Within each category, one can identify many possible indicators that have already been published, and are used either for research, for general educational purposes, or in some cases, for decisionmaking. It is beyond the intent of this paper to be comprehensive in terms of summarizing existing indicators. However, it is possible to provide examples in several of the categories shown above. In these categories, an indicator that serves as an example is identified and discussed briefly. Two of the categories, physical climate and sectors of concern, have several examples because they are so broad-ranging. Sectors and resources of concern also has indicators that are still very much research topics. The last category, adaptation and mitigation responses, however, has no indicators currently identified. This situation is explored further in Section 7, Research Needs.

In the NCA process, the background work to establish specific questions of relevance to stakeholder communities, document how proposed indicators respond to those concerns, and select indicators for the overall system has not yet been done. Thus, the indicators here are presented only as candidates for the indicators that might be chosen. But the list is by no means comprehensive, and the final selection of indicators will involve decisions about adequacy of the indicators themselves, adequacy of the underlying data, and the ability to track the indicators over time. 


\subsection{Greenhouse Gas Emissions and Sinks}

\subsubsection{U.S. Greenhouse Gas Emissions}

EPA's greenhouse gas (GHG) emissions indicator focuses on emissions of carbon dioxide, methane, nitrous oxide, and several fluorinated compounds-all important greenhouse gases that are influenced by human activities (U.S. EPA, 2010). These gases are covered under the United Nations Framework Convention on Climate Change, an international agreement that requires participating countries to develop and periodically submit an inventory of greenhouse gas emissions. Data and analysis for this indicator come from EPA's Inventory of U.S. Greenhouse Gas Emissions and Sinks: 1990-2009 (www.epa.gov/climatechange/emissions/usinventoryreport.html; EPA, 2011). This indicator is restricted to emissions associated with human activities.

This indicator reports emissions of greenhouse gases according to their global warming potential, a measure of how much a given amount of the greenhouse gas is estimated to contribute to global warming over a selected period of time (Figure 5). For purposes of comparison, global warming potential values are given in relation to carbon dioxide and are expressed in terms of carbon dioxide equivalents (Figure 5). For additional perspective, this indicator also shows greenhouse gas emissions in relation to economic activity and population (Figure 6).

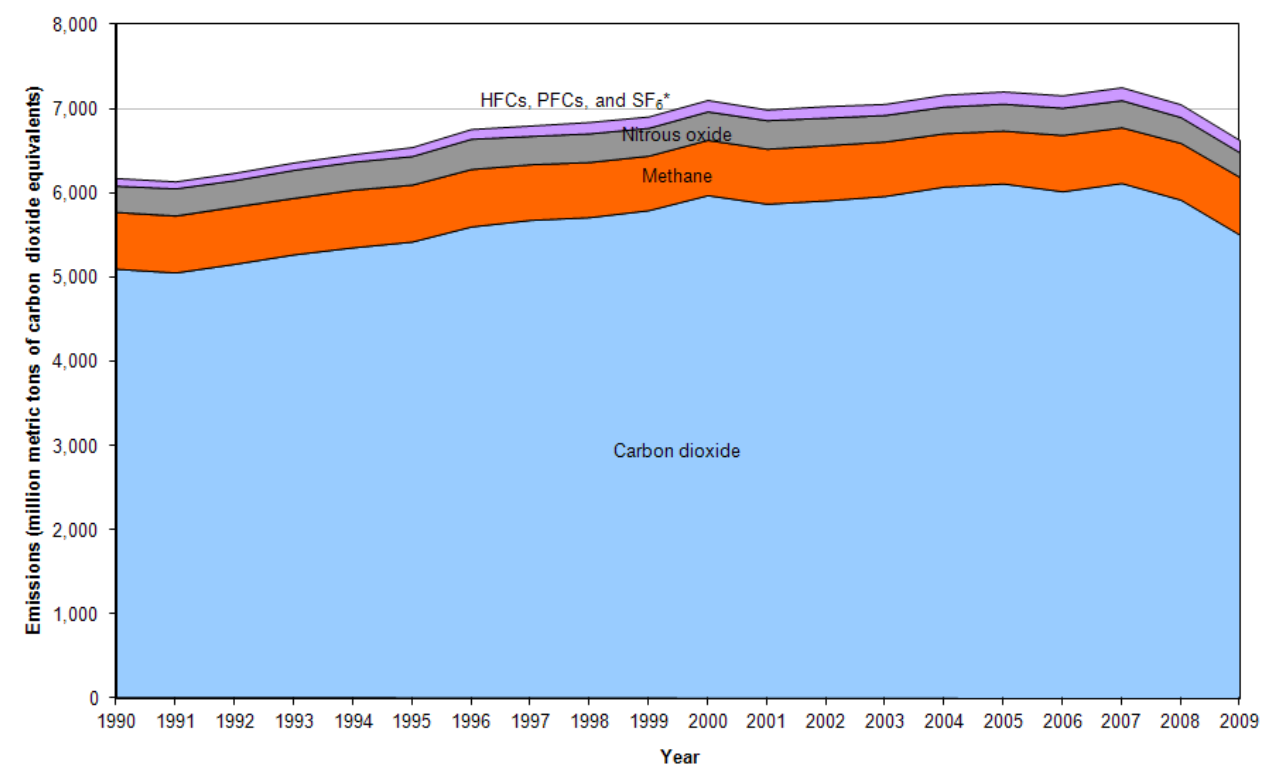

Figure 5. U.S. Greenhouse Gas Emissions by Gas, 1990-2009. This figure shows emissions of carbon dioxide, methane, nitrous oxide, and several fluorinated compounds in the United States from 1990 to 2009. For consistency, emissions are expressed in million metric tons of carbon dioxide equivalents. * HFCs are hydrofluorocarbons, PFCs are perfluorocarbons, and SF6 is sulfur hexafluoride. 


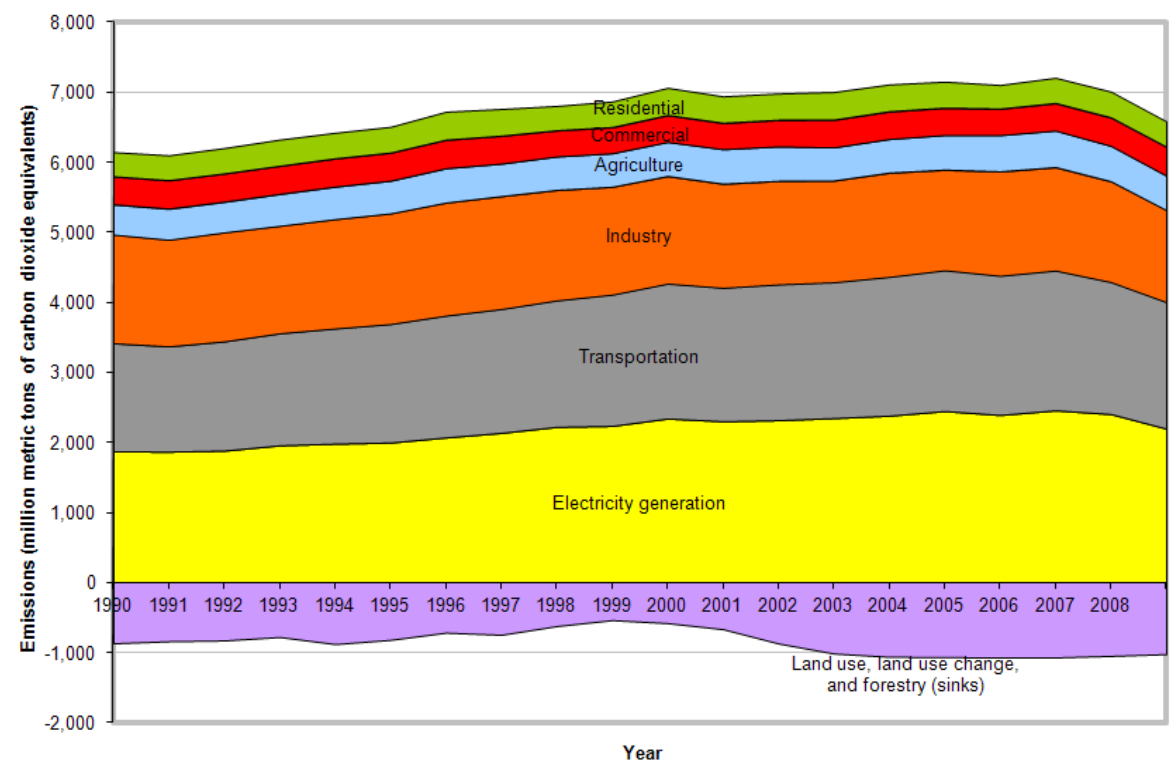

Figure 6. U.S. Greenhouse Gas Emissions and Sinks by Economic Sector, 1990-2009. This figure shows greenhouse gas sinks and emissions by source in the United States from 1990 to 2009. For consistency, emissions are expressed in million metric tons of carbon dioxide equivalents. Totals do not match Figure 7 exactly because the economic sectors shown here do not include emissions from U.S. territories.

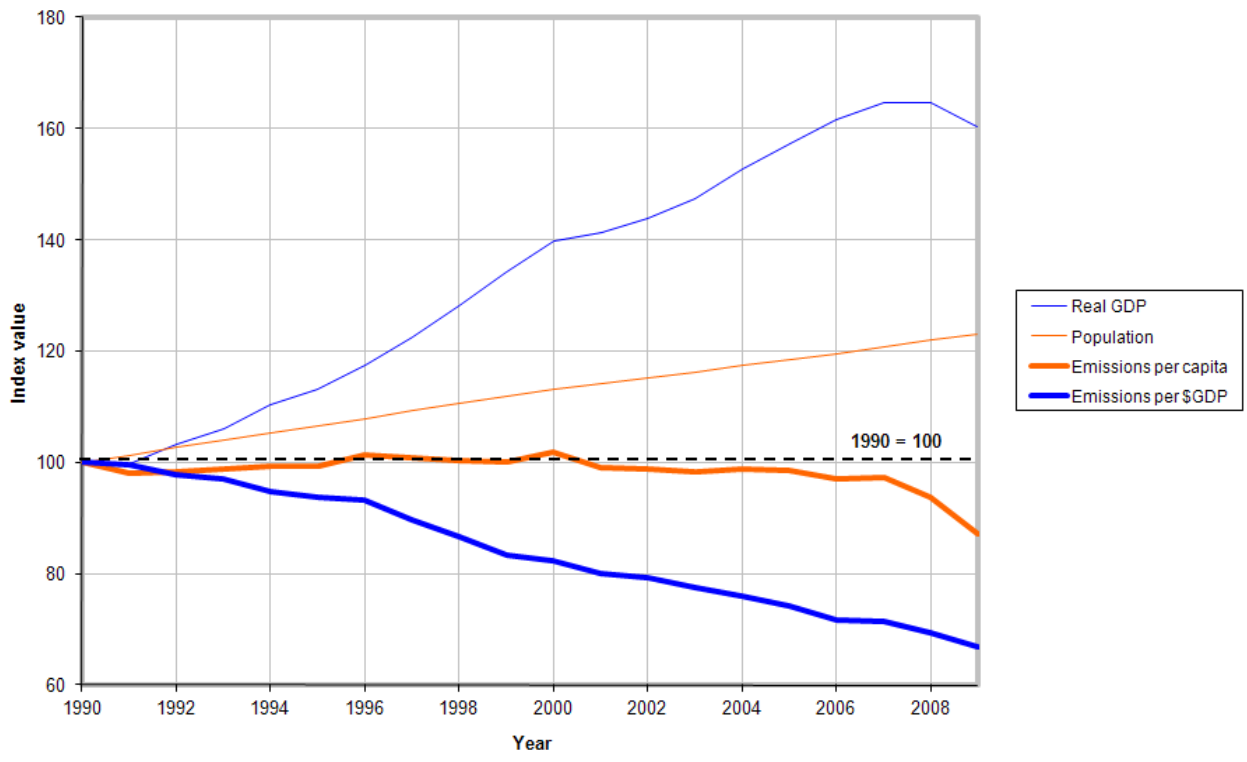

Figure 7. U.S. Greenhouse Gas Emissions per Capita and per Dollar of GDP, 1990-2009. This figure shows trends in greenhouse gas emissions from 1990 to 2009 per capita (heavy orange line), based on the total U.S. population (thin orange line). It also shows trends in emissions compared with the real GDP (heavy blue line), which is the value of all goods and services produced in the country during a given year, adjusted for inflation (thin blue line). All data are indexed to 1990 as the base year, which is assigned a value of 100; thus a value of 140 in 2000 would represent a 40 percent increase since 1990.

The calculations in Figure 7 are based on GDP and population data provided by the U.S. Bureau of Economic Analysis and the U.S. Census, respectively. 
EPA is now collecting facility-level data on greenhouse gas emissions and other relevant information under the Greenhouse Gas Reporting Program. U.S. facilities that emit 25,000 metric tons or more per year of greenhouse gases are required to submit annual reports. The rule pertains to direct emitters, certain fuel and industrial greenhouse gas suppliers, and facilities that inject carbon dioxide underground for geologic sequestration, enhanced oil recovery, or other purposes. The GHG data provides a critical tool for businesses and other innovators to find cost- and fuelsaving efficiencies that reduce greenhouse gas emissions, and foster technologies to protect public health and the environment. Over time, EPA will also use this data to improve emissions estimates from certain sources in EPA's Inventory of Greenhouse Gas Emissions Sinks. For more information, see: http://www.epa.gov/climatechange/emissions/ghgdata.html.

\subsection{Atmospheric Composition}

\subsubsection{The Aggregated Greenhouse Gas Index}

The Aggregated Greenhouse Gas Index (AGGI) is a prominent indicator constructed to assess, from year to year, the increase in cumulative direct radiative forcing of the major long-lived GHGs (carbon dioxide, methane, nitrous oxide, CFC-12, and CFC-11) and fifteen other gases. Taken individually, each time series of a particular gas concentration is itself an indicator. Collectively, their greenhouse properties are combined into an aggregated indicator to represent a major driver of long-term climate change and to account for the vast majority of radiative forcing above a preindustrial baseline state. The annual AGGI value is expressed as the change from a reference year (1990, the Kyoto Protocol baseline year). It is presented in the units of radiative forcing (watts per meter squared) and as a percent change relative to the baseline year.

Although AGGI is a composite indicator, the component gases are tracked separately and AGGI is often presented in tables and graphics broken out into these components (Figure 8). This breakout approach is useful for assessing the relative importance of each component and how these have changed over time.

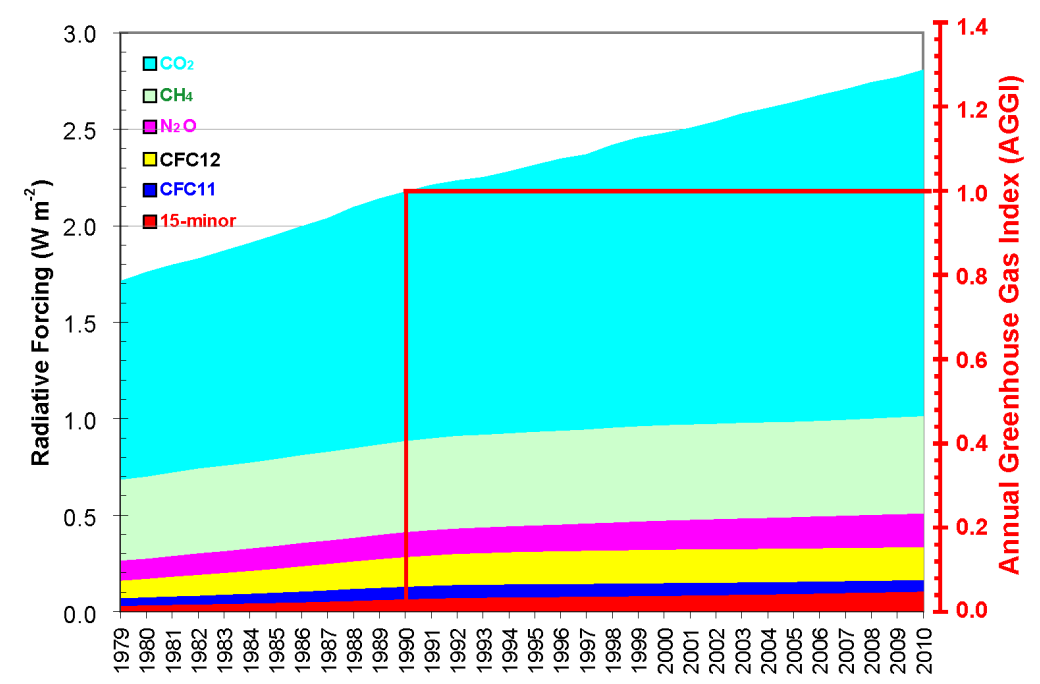

Figure 8. The Aggregated Greenhouse Gas Index (AGGI). 


\subsection{Physical Climate Variability and Change}

\subsubsection{Temperature and precipitation}

These indicators are straightforward spatial averages of two very basic weather elements. A robust record dating to 1895 is possible due to the early establishment and long-term adequate support of the underlying observing network(s) for each. For these variables, and indicators strictly dependent on them, it is possible to provide nested spatial scales at points along a local-area-state-regionalnational-hemispheric-global continuum (Figure 9), although methods and presentation differ somewhat for domestic versus international indices. Each spatial scale is addressed with a time series of the spatial average (e.g., the average temperature for a region over time) and measures of deviation from that state over time (e.g., historical rank or measures of unusualness like the Standardized Precipitation Index).
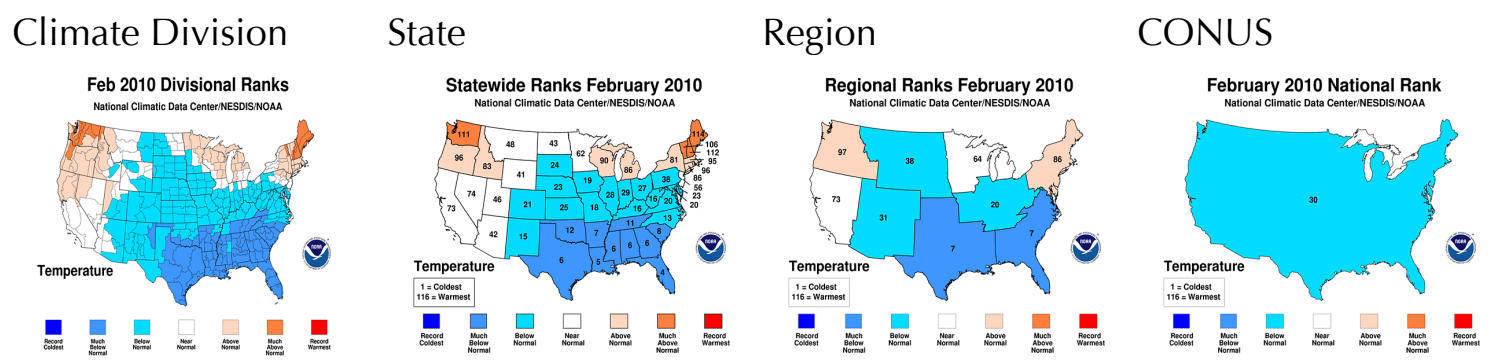

Figure 9. The nested spatial scales for which NCDC provides routine temperature (shown), precipitation, and some drought monitoring. Each scale uses the same underlying observational data.

\subsubsection{Climate Extremes Index (CEI)}

The Climate Extremes Index (Gleason et al., 2008) is a composite of six individual components representing specific climate extremes within the contiguous United States. The six components are: maximum temperature, minimum temperature, Palmer Drought Severity Index, days with/without precipitation, one-day precipitation, and the intensity U.S. landfalling of tropical cyclones. The CEI defines "extreme" to mean a value among the outermost ten percent of the historical record for a given grid point. For each component and time period (month, season or year), the CEI assigns a regional/national score based upon the total area (aggregation of grid points) in extreme conditions. These components are averaged to provide a composite index, which captures a broader representation of the climate system than any individual component.

\subsubsection{Drought Indicator}

Droughts are a normal part of the climatic cycle and they can occur in any climate regime around the world, including deserts and rainforests. Drought is also the most damaging and least understood of all natural hazards (Wilhite 2000). It is difficult to determine its onset and termination and its impacts can extend over a larger geographical area than have other natural hazards in historic times. The effects of drought tend to accrue slowly over time and can linger for years even after the termination of the drought. Of course, the effects of drought are influenced, for better or worse, by the decisions made to cope with or mitigate their effects. Environmental changes involving crescive or incremental and cumulative problems usually receive little attention in their early phases as decision and policymakers choose to deal with more immediate concerns (Grasso 2009). As these crescive events go unaddressed they can eventually become an urgent crises that is more costly to manage. A drought should never surprise anyone yet it often does. Perhaps no other hazard lends itself quite as well, then, to using indicators and indices than 
drought, given its slow onset and overall difficulties with how to characterization it (Heim 2002). This section describes one of the primary composite or hybrid indicators used to monitor drought in the U.S. Generally there are four basic drought types: 1) meteorological; 2) agricultural; 3) hydrological; and 4) socioeconomic, and there are indices and indicators associated with each (Wilhite and Glantz, 1985). There is no one index or indicator, however, which adequately describes all aspects and types of drought (Svoboda et al. 2002; Hayes et al. 2011). Given the complexity of drought a systematic approach is described that can integrate multiple drought indicators or indices in a single representation that decision and policy makers can use to understand and respond to drought in their state or region. In recognition of these issues, the National Integrated Drought Information System (NIDIS) Act was passed 2006 to develop next generation drought monitoring products to support policy, planning and decision-making across all spatial and temporal scales.

\subsubsection{Composite Drought Indicator: U.S. Drought Monitor}

There are typically three approaches to drought assessment: a single indicator or index; multiple indictors or indices; or, composite or hybrid indicators. Traditionally, decision makers or researchers employed one indicator or an index due to availability, familiarity, or time constraints. Over the past 10 years, however, there has been increasing global interest and growth in developing several new drought indices based on various indicators. This interest has given decision and policy makers more choices, though, there has not always been a clear way of synthesizing them into something simple enough to understand by non-scientists or relay to the public. With the advent of geographic information systems (GIS) and increased computing and display capabilities, the ability to overlay and compare various indicators or indices became prominent. Over the past decade, a new type of composite indicator has emerged in several forms as a means of merging several indices together. A composite index is a grouping, or combining of various indices into a single index. The idea is to use the strengths of a variety of inputs, yet maintain a single, simple source of information for decision and policy makers or the public. One of the most widely used composite indicators is the U.S. Drought Monitor (USDM) (http://droughtmonitor.unl.edu). The USDM integrates multiple data sources and derivative products from local to national scales (Svoboda et al. 2002). The USDM is also unique in that it incorporates feedback and input into the process by maintaining and utilizing an expert user group of over 300 people from across the U.S. who serve as a ground truth against the indicators by providing data and products at a local scale. A convergence of evidence approach is used to combine the indices with impacts and feedback from experts through an iterative process each week. A classification scheme was chosen that was familiar with the hazard community and the general public such as the Staffir-Simpson Hurricane Wind Scale. The classification system is based on the utilization of a ranking percentile approach. This approach gives historical context to any index value in that it shows the percentage of values in its frequency distribution and thus allows for the comparison of multiple indices. The classification categories run from D0-D4, where D0 is equal to "abnormally dry" (30th percentile) conditions and is not a drought category but signifies the potential for drought; D1 is considered "moderate drought" (20th percentile); D2 is "severe drought" (10th percentile); D3 is "extreme drought" (5th percentile); and D4 is considered "exceptional drought" (2nd percentile). 


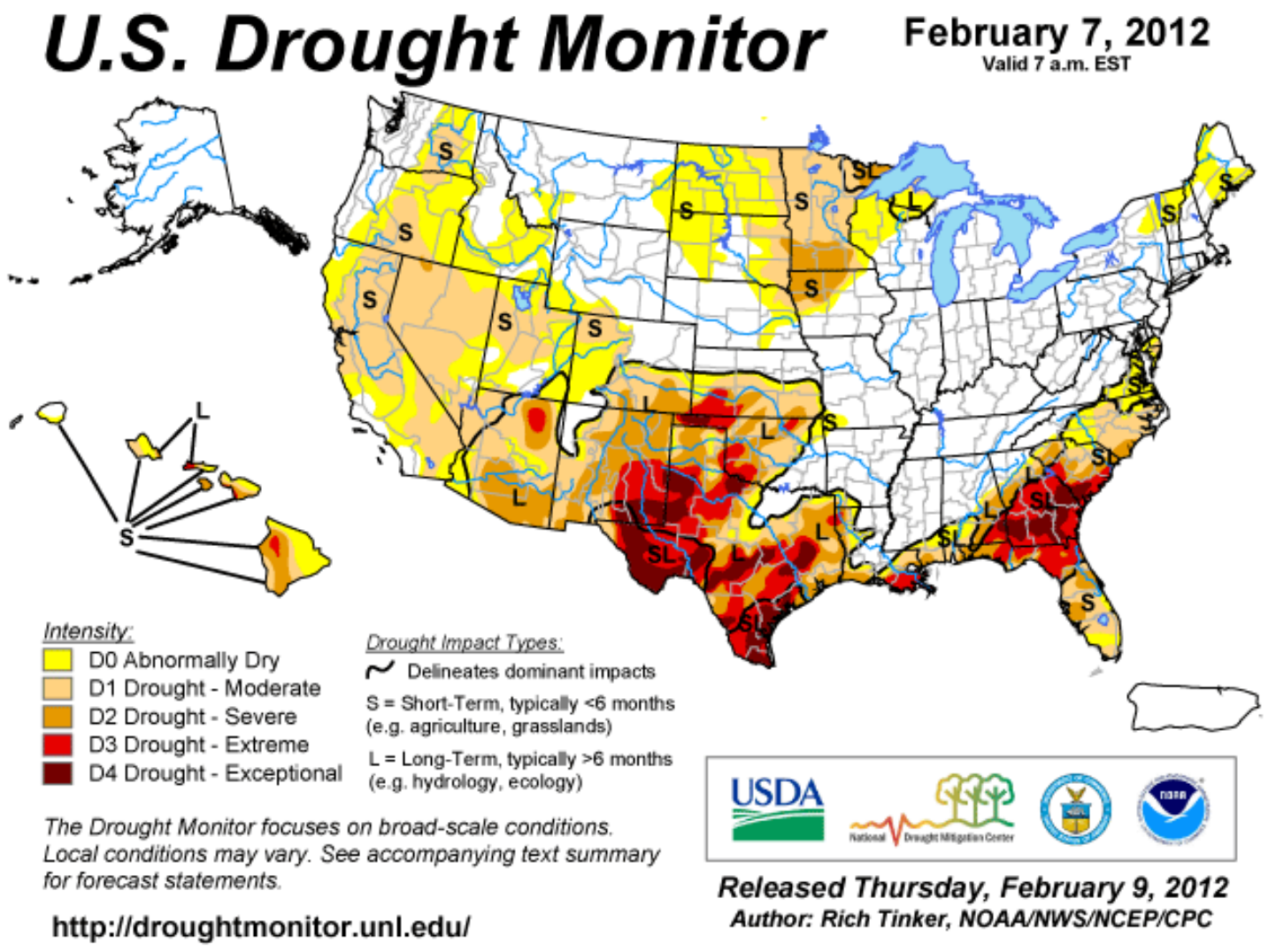

Figure 10. The U.S. Drought Monitor (USDM) map for February 2, 2012. The USDM is released every Thursday and is a coordinated effort by USDA, National Drought Mitigation Center, and NOAA.

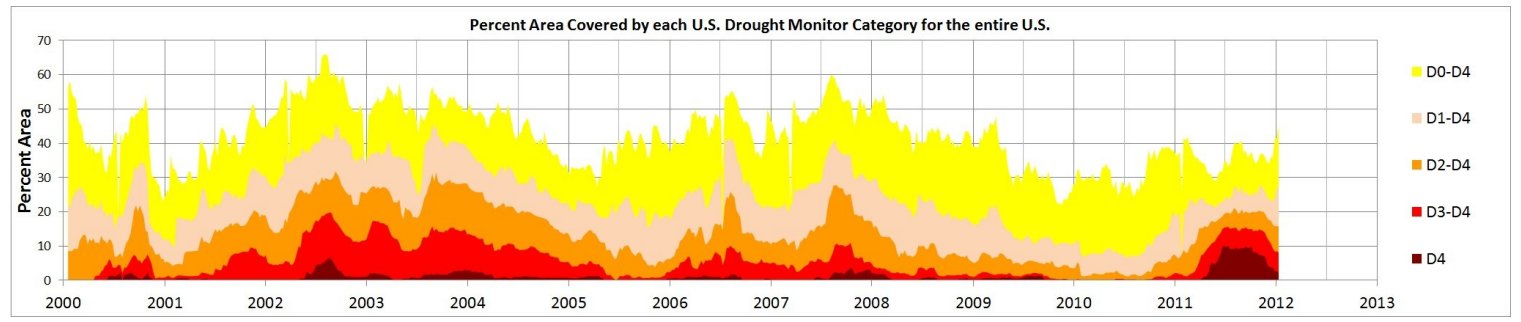

Figure 11. Percent area of U.S. lands classified under drought conditions from 2000 through 2011.

\subsubsection{U.S. Drought Monitor in Practice}

The USDM has been produced weekly since 1999 and involves collaboration between the National Drought Mitigation Center at the University of Nebraska, the United States Department of Agriculture Joint Agricultural and Weather Facility, and the National Oceanic and Atmospheric Administration through the Climate Predictions Center, the NCDC and Western Regional Climate Center. The USDM map covers the U.S. including Alaska, Hawaii, and Puerto Rico (Figure 10). The USDM map can be represented in a number of ways. One of the most useful applications is to look at the percent area of lands classified under drought conditions for the U.S. This can also be done for a specific region or by state and can be calculated from 2000 to present. For example, looking at the U.S. including Puerto Rico, there is no clear increasing or decreasing trend in 
intensity or spatial coverage over the last decade (Figure 11). It should be noted there are indicators with longer periods of record that exist, namely the Palmer Drought Severity Index (PDSI). Consistent with the USDM (of which the PDSI is one of the indicators used), though, the PDSI shows relatively no trend with respect to drought extent for the U.S. since 1900 .

The USDM is also used as one of the primary inputs to the U.S. Seasonal Drought Outlook (SDO) produced by the Climate Prediction Center (Figure 12). The SDO depicts large-scale trends based on short and long-range forecast combined with the USDM to show where drought could develop, persist, intensify, or improve. The SDO is primarily a forecast and not necessarily an indicator, however. When paired with the USDM and as part of a larger early warning effort (see NIDIS Implementation Plan) the SDO is a very effective tool for informing decision makers and the public where drought may improve or intensify over the next three months.

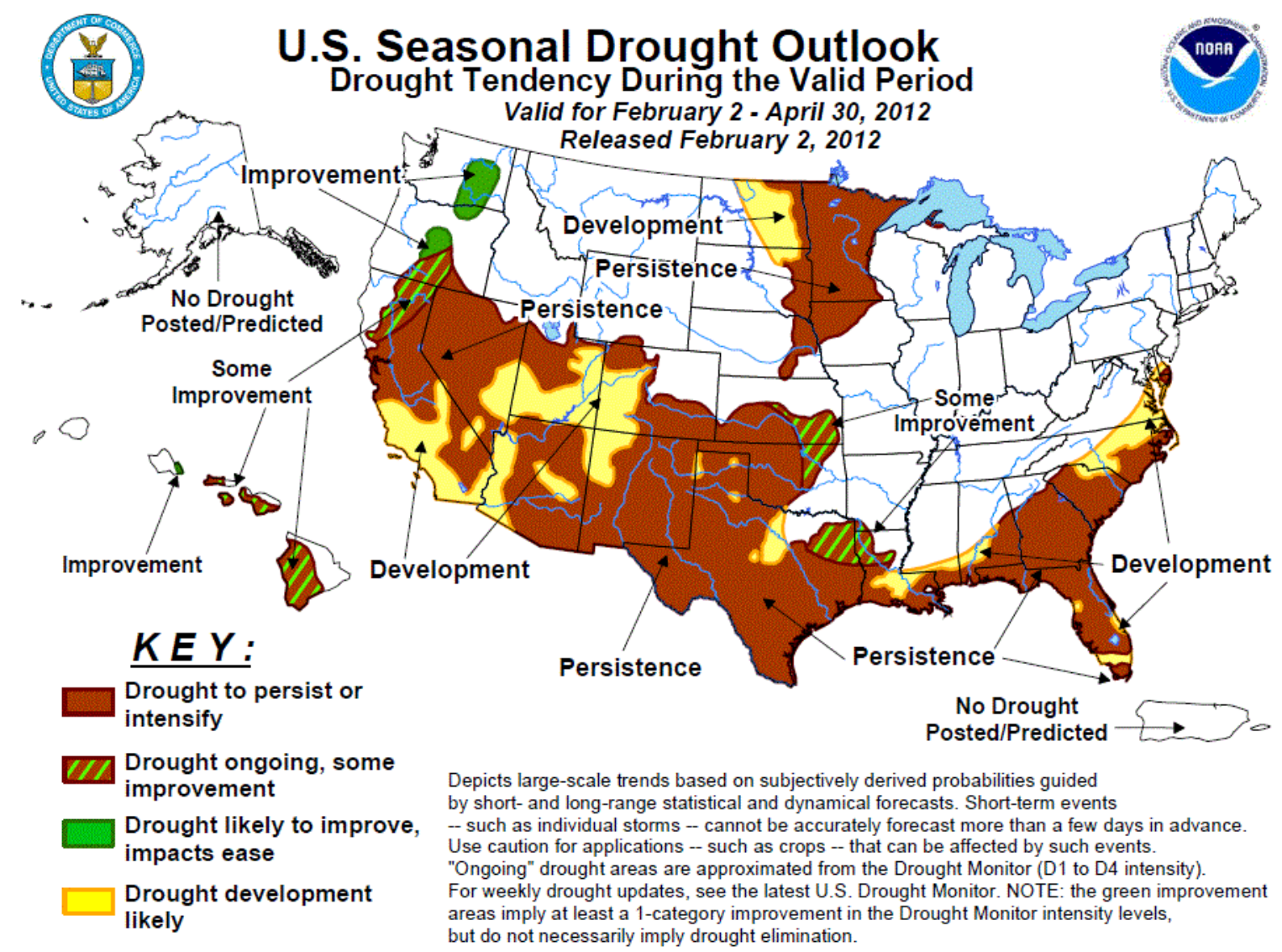

Figure 12. The U.S. Seasonal Drought Outlook is released every month and is a three-month outlook or forecast for the U.S. that shows where drought could improve, intensify, or develop.

The USDM is also being used as a trigger that initiates and/or terminates specific management responses or actions. For example, the USDM is becoming recognized as a useful indicator for state drought plan triggers and it is also being used by several programs in the U.S. Department of Agriculture's (USDA) Farm Service Agency (FSA). The USDM is informing FSA of conditions in areas seeking approval of emergency haying and/or grazing through the Conservation Reserve Program as well as grazing losses due to drought under the Livestock Forage Disaster Program (Figure 13). For the Non-Fat Dry Milk Program, the USDA is using the USDM to determine which counties are eligible for USDA surplus stocks of non-fat dry milk for livestock producers in areas 
affected by drought. The Internal Revenue Service is also using the USDM for tax deferrals for livestock producers that involuntarily sold livestock due to drought conditions.

In addition to being used as a trigger the USDM is used by the major media outlets and by the U.S. Congress and state governor offices as a easy way to depict and communicate drought on a state, regional, or national scale. Also, the USDM will likely play a critical role by providing a historical reference or probability of occurrence (return period) for a given drought magnitude in a particular state or region; especially as its record grows. Using the USDM to calculate return periods will inform planning and design applications. The USDM is also serving as a critical component for the establishment of regional drought early warning information systems by the National Integrated Drought Information System (NIDIS Implementation Plan, 2007)

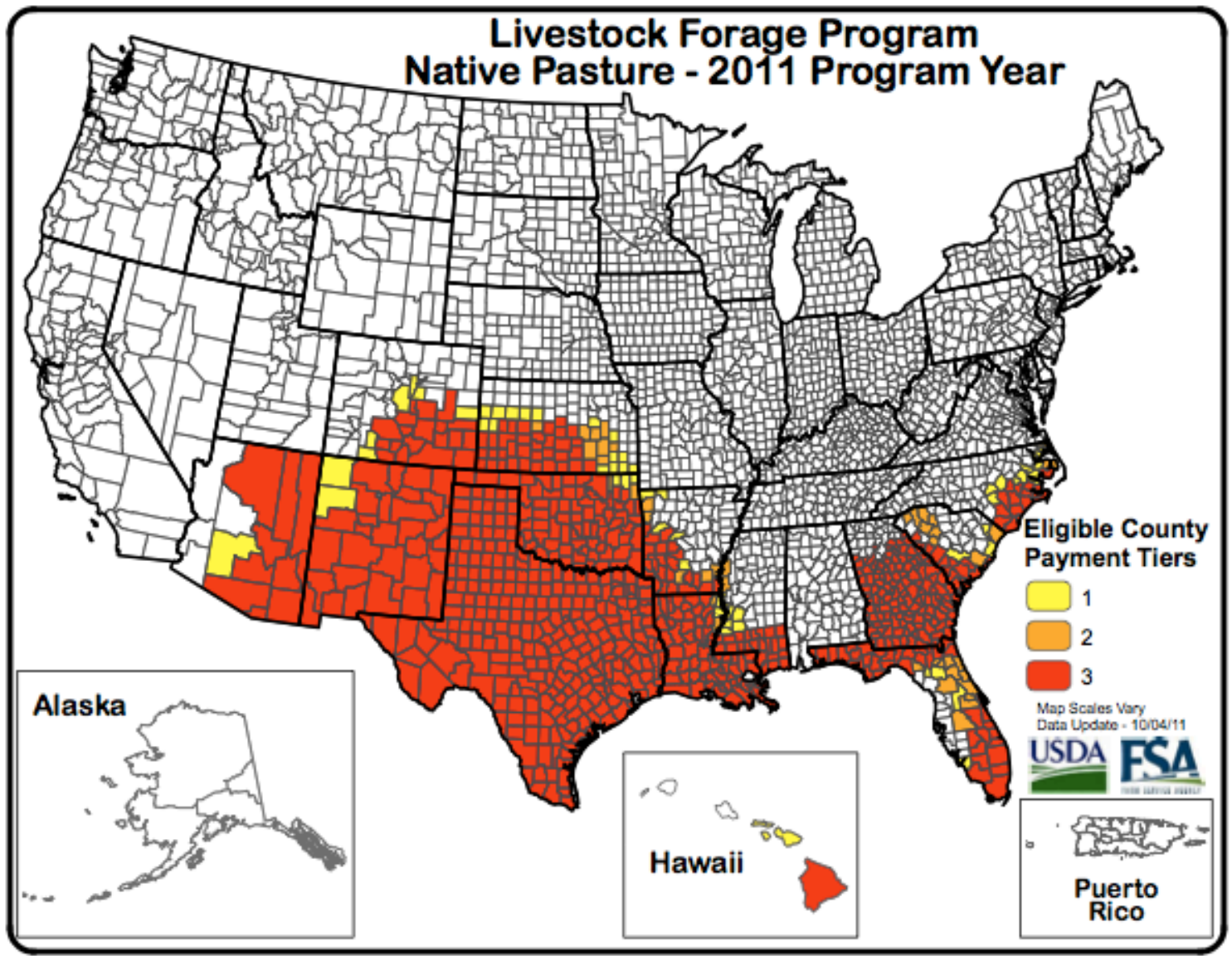

Figure 13. Livestock Forage Program (LFP) Eligibility Map for 2011 program year for native pasture. The map depicts LFP program eligibility by county for the US and Puerto Rico, based on grazing periods and drought intensity for native pasture. 


\subsection{Sectors and Resources of Concern}

\subsubsection{The State of Arctic Sea Ice}

During 2011, Arctic sea ice continued its downward trend. The areal extent remained much below normal throughout the year (Figure 14). In September, when Arctic sea ice drops to its annual minimum, the monthly average extent was 4.61 million square kilometers $(1.78$ million square miles), 35\% below the 1979-2000 average and the second lowest extent in the satellite record dating back to 1979 (Figure 14). The five-year period from 2007-2011 encompasses the five lowest extents in the satellite record, including the record minimum in 2007. The monthly September trend from 1979 through 2011 is $-84,700$ square kilometers $(-32,700$ square miles) per year or $12 \%$ per decade relative to the 1979-2000 average (Figure 14). These estimates are from the National Snow and Ice Data Center using data and methods developed by scientists at the NASA Goddard Space Flight Center.
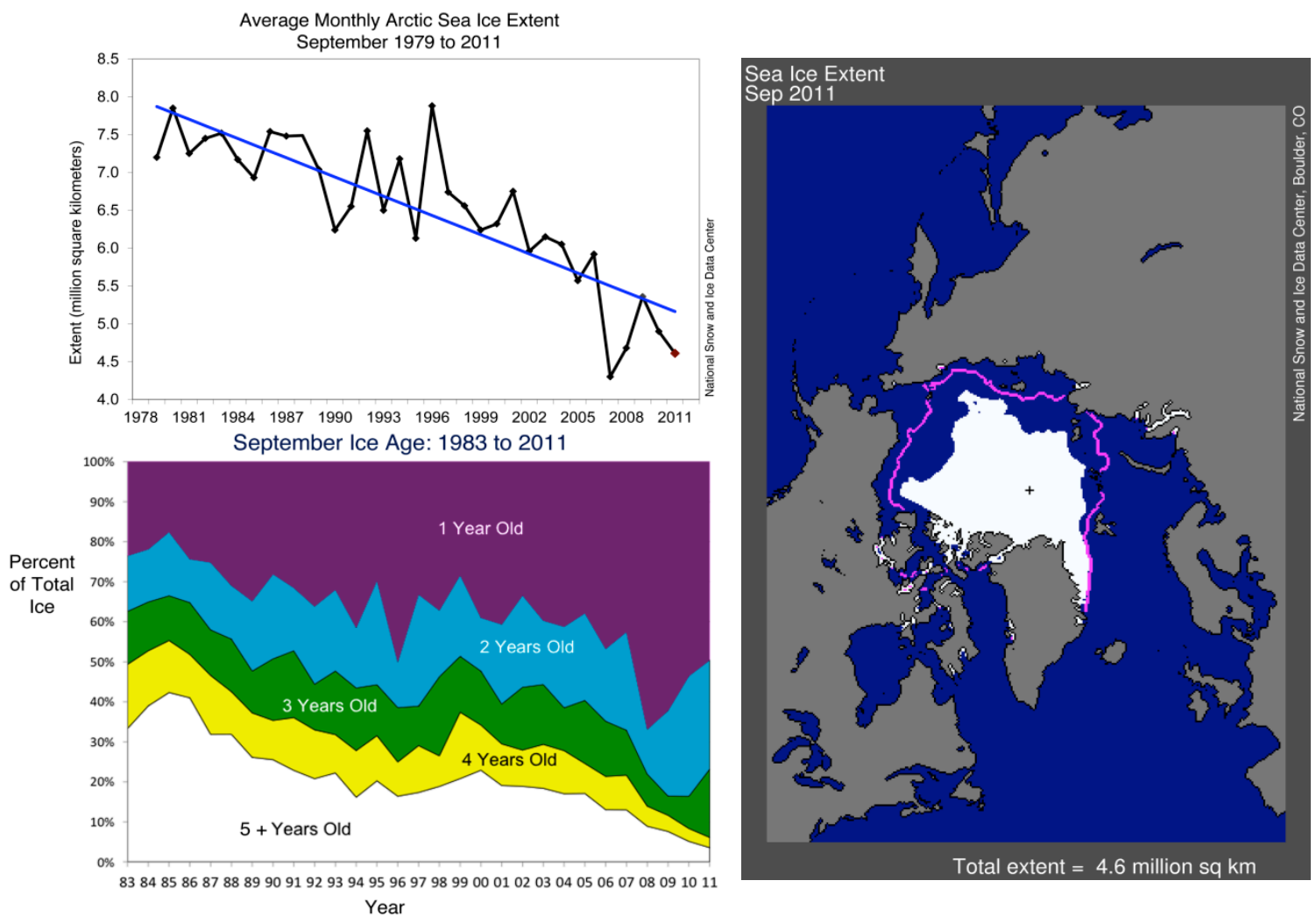

Figure 14. Upper left: September monthly average total sea ice extent time series; lower left: percent composition of ice cover by ice age; right: monthly average extent field for September 2011 and, in pink, the 1979-2000 median extent.

Sea ice thickness and volume are less well-quantified, but several methods strongly indicate that sea ice is now much thinner than historic levels and that the sea ice cover is becoming dominated by thinner, seasonal ice (ice that grows during the winter and then melts completely over the summer). This is in contrast to earlier decades when most of the Arctic Ocean was covered by thicker, perennial sea ice that remained through several summers. Satellite-derived ice age data, from Maslanik at the University of Colorado, indicate that the oldest sea ice, more than five years old, which once used to cover $30-40 \%$ of the Arctic Ocean, has virtually disappeared. The data 
also shows some increase in 2-3 year old ice, suggesting there could be at least a temporary stabilization of the perennial ice cover (Arctic Sea Ice News and Analysis, 2012). However, more of the perennial ice is being lost due to summer melt than in the past, limiting the ability of the ice cover to recover.

A combined modeling and observation estimate of Arctic sea ice volume, developed by Zhang and Lindsay at the University of Washington indicate a continuing decline in volume it may have reached a record low in September 2011 (Arctic Sea Ice Volume, 2012). The loss of older ice and the decline in ice volume has been corroborated by in situ buoy measurements from the U.S. Army Cold Regions Research (Ice mass balance buoys, 2012) and Engineering Laboratory and satellite-derived ice thickness estimates from the NASA Ice, Cloud, land Elevation Satellite (ICESat; ICESat, 2012).

\subsubsection{Net Primary Productivity Trends}

Net primary production (NPP) is the annual net biomass growth of all plant material on a unit of land. A global annual calculation of terrestrial NPP is being continuously produced since 2000 by the NASA Earth Observing System MODIS Land Science team. The algorithm combines MODIS vegetation data with daily global meteorology at $1 \mathrm{~km}^{2}$ resolution (Running et al., 2004; Zhao and Running, 2010).

Maps of biophysical data are most easily interpreted when they are a relative anomaly, or departure from a "normal" or baseline condition rather than absolute units that may not be familiar to users who are not scientists. A well-built anomaly map will implicitly define normal as the 0 point, with departures above or below normal that are deemed significant colored in clearly opposing colors. The width of the 0 point implies non-significant variability.

The map of annual anomaly of NPP is produced by first computing the 12 year average, 2000 2011, of annual NPP, then the current year NPP is compared against the average (Figure 15). The result clearly identifies regions with above or below average plant growth that year. These data informs agricultural yield measures, and carbon source/sink dynamics. So, for example the time series of maps in the figure show that the southern U.S. is the area where NPP is most variable from year to year, sometimes much below longer-term averages (red) and sometimes above (blue). 


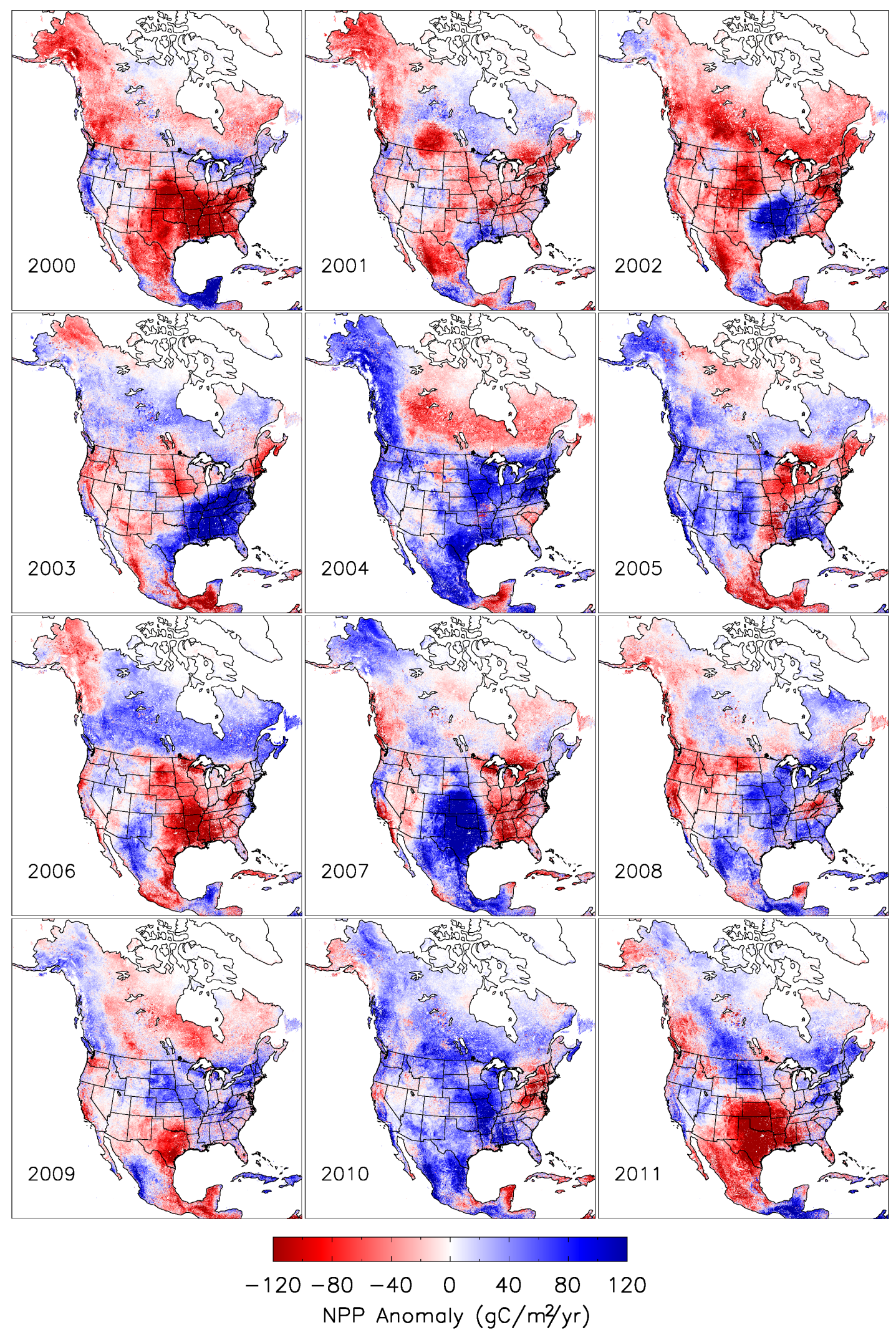

Figure 15. Example of MODIS NPP anomaly mapping of North America. 


\subsubsection{Agricultural Indicators}

Agriculture is largely defined by prevailing climate and edaphic conditions. As such, locally or regionally, changes in key climate variables (e.g., changes in seasonal mean temperatures or changes in seasonal precipitation patterns) can affect changes, perhaps significant changes, in the mix of commodities produced and the systems farmers employ to produce them. Agriculture is also a major economic sector with over 2 million farms, 900 million acres in farms, and gross farm income between $\$ 300-\$ 350$ billion annually. Supporting agriculture are a variety of private and public sector industries and organizations that spend billions of dollars annually to provide research, education, improved technologies, and marketing aimed at expanding commodity production possibilities, increasing productivity, improving input use efficiency (including energy, water, and nutrient use as well as developing new plant varieties and livestock breeds), and increasing farm profitability. With the help of these industries and organizations, the farm sector has long history of innovating and adapting to changing economic, environmental, legal, and climate conditions. For example, in 1910 U.S. farmers cultivated 330 million acres and supplied food and fiber to population of 92.2 million. In 2006, U.S, farmers cultivated 330 million acres and supplied food and fiber to a population of 297.5 million.

The numerous factors that can affect changes in where and how different commodities are produced in the U.S., make it difficult to identify specific indicators that unambiguously show that climate change is affecting agriculture, or, that agriculture is responding to it. Rather, what is needed is a suite of indicators that, viewed collectively, present a compelling case that farmers are being impacted by a changing climate and/or are responding to it. Such a suite will need to measure and track changes in at least four broad categories of impacts; the state of soil resources, commodity (crops and livestock) distribution and production, distribution and impact of pests, and net economic impacts on farmers (individually, regionally, and nationally). Four potential indicators are described below. The data needed to develop these indicators are either currently available or would be relatively straightforward to collect. The indicators described should be viewed as illustrative. A broader set would be required to capture a comprehensive picture of the interface between climate change and U.S. agriculture.

Workable Field Days during the Growing Season: Excessive soil moisture due to floods, storms, snowmelt or other weather related events can delay planting dates and reduce the number of days suitable for field operations. For example, existing data on workable field days in Midwest shows that higher than average precipitation levels in recent years have reduced the number of workable field day during April and May. Viewed over a period of time, regional changes in the number of workable field days - particularly in the spring when most planting occurs - could indicate areas where changing climate conditions are impacting crop production systems.

Crop Distribution Maps: USDA collects county-level data on acres planted for the major program crops. These data can be (and are) used to develop maps showing the distribution of production for these commodities over the United States and over individual States. Over a period of time, changes in the distribution of commodity production could indicate how and where farmers are adjusting crop production to changing climate conditions.

Pest Distribution Maps: Climate change will likely increase the challenges farmers face from agricultural pests (including weeds, insects, and diseases). For example, earlier springs and warmer temperatures may result in northern migration of many insect and weed pests, higher winter survival rates for existing pathogens and diseases, and conditions favorable to new pests becoming 
established. Developing pest distribution maps would provide and indicator of how agricultural pest populations may be responding to changing climate conditions.

Disaster and Crop Insurance Payments: For decades USDA has provided crop insurance and disaster assistance payments to farmers who have incurred eligible crop losses due to various weather and weather related events - including drought, flood, hail, freeze, severe storms, rationing of irrigation water, pest infestations, and disease outbreaks. Annual data on crop insurance and disaster assistance payments allow identification of payments by type of weather event and State of recipient. Climate change will likely increase both the intensity and frequency of the above events. The disaster assistance and crop insurance programs are a potential source of data from which a number of indicators can be developed that reflect the net economic stress changing climate conditions may be having on farmers (in aggregate, regionally, and by type of event).

\subsubsection{Bioclimatic Indicators of Spring}

Changes in the timing of phenological events—such as flowering, migrations, and breeding — can serve as a "globally coherent fingerprint of climate change impacts" on plants and animals (Parmesan 2007). Climate-induced changes in phenology have been linked to shifts in the timing of allergy seasons and cultural festivals, increases in wildfire activity and pest outbreaks, shifts in species distributions, declines in the abundance of native species, the spread of invasive species, changes in agricultural yield, and changes in carbon cycling in natural ecological systems.

Local to regional climatology is a critical driver of phenological variation of organisms across scales from individuals to landscapes (Karl et al., 2009, Rosenzweig, 2007). Because plants respond to the cumulative effects of daily weather over an extended period, their development stages are effective integrators of climate data. One specific measure, first appearance of spring foliage, is particularly important because it often shows the strongest response to temperature change, and is crucial for accurate assessment of processes related to start and duration of the growing season (U.S. EPA, 2010).

Schwartz et al. (2006) developed a suite of modeled and derived measures (produced from daily maximum-minimum temperatures) linking plant development (based on historical data from leafing and flowering of lilac and honeysuckle) with basic climatic drivers to provide a reliable and spatially extensive method for monitoring general impacts of global warming on the start of the growing season. These spring indices models can be generated at any location that has daily maximum-minimum temperature time series, so they can be produced and evaluated over broad geographic areas. In addition, the model output is spatially and temporally consistent because spring indices circumvents issues associated with differential response among species, as well as variations in methodology or human observers. 


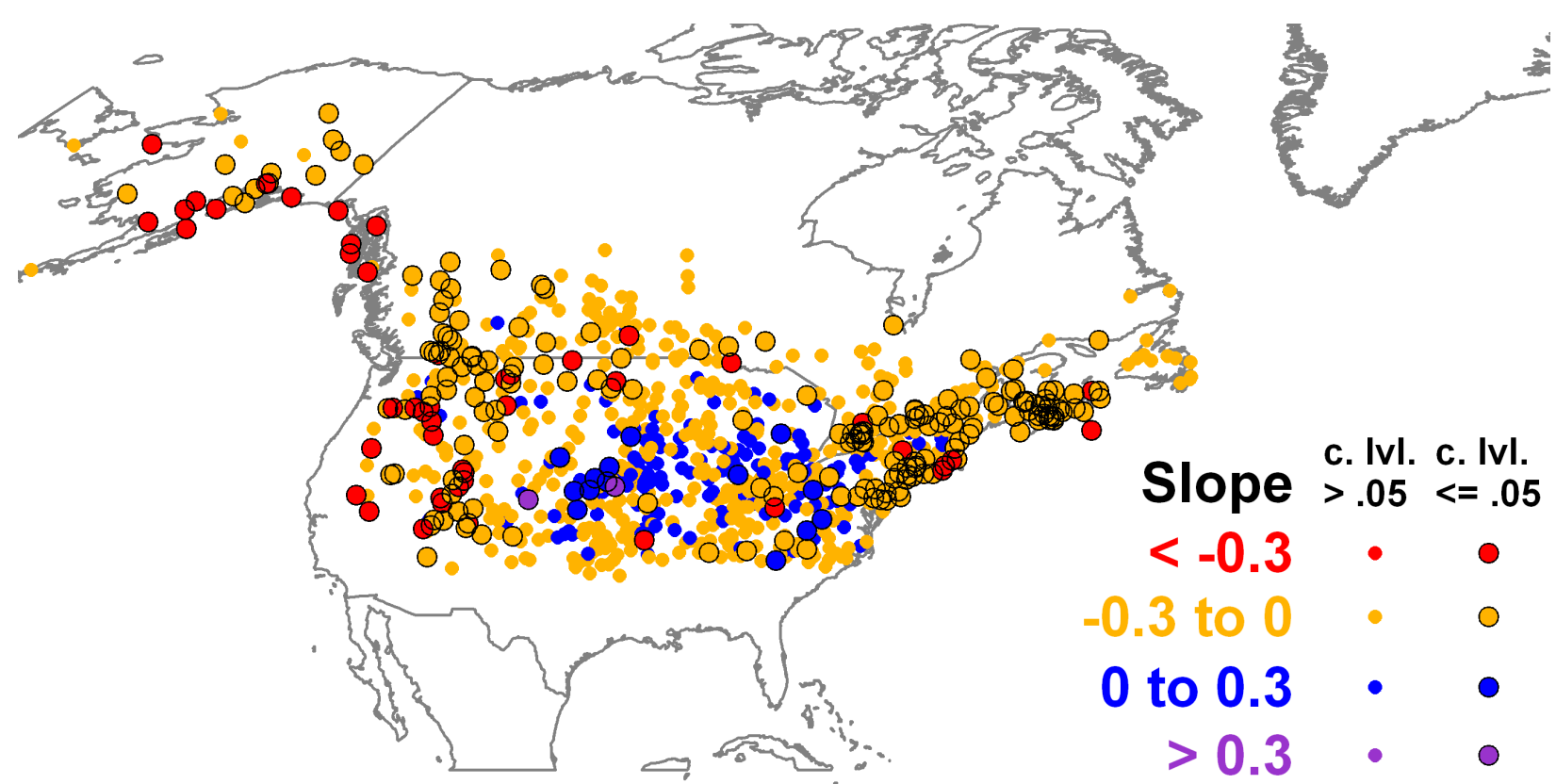

Figure 16. Spring indices first bloom date 1961-2000 trend by station in North America. Trend values are in days per year and colors show categories. Stations with trends significant at the 0.05 level or better are shown with larger symbols outlined in black (previously unpublished figure from analyses/results reported in Schwartz et al. 2006).

Application of the spring indices models to temperate regions of the Northern Hemisphere indicated an advance of early spring warmth (spring indices first leaf date, -1.2 days/decade), late spring warmth (spring indices first bloom date, -1.0 days/decade), and last spring freeze date (-1.5 days/decade), from 1955 to 2002, and demonstrated spatial differences in relative timing of the onset of spring and last spring freeze dates (Schwartz et al. 2006). Spring indices models also revealed recent (1959-1993) regional variations in the timing of spring's onset across the continental U.S., with dates moving earlier at a faster rate in the Northeast and Northwest than in other areas (Schwartz and Reiter 2000).

\subsubsection{Heat-Related Mortality as a Climate Change Human Health Indicator}

Extreme heat events, characterized by consecutive summer days of high maximum and minimum daily temperatures, are the most prominent cause of weather-related human mortality in the U.S., responsible for more deaths than flooding, lightning, hurricanes, tornados, and earthquakes combined (Luber and McGeehin, 2008). From 1999 to 2003, a total of 3442 heat-related deaths were reported in the U.S. (CDC, 2006). People most vulnerable for dying during a heat event include the elderly, poor, urban dwellers, socially isolated, and those suffering from some preexisting health conditions such as heart disease and obesity (Semenza et al., 1996). Increasing urbanization combined with an aging population and limited support networks for the poor will increase both the size and the vulnerability of the at-risk populations in coming decades.

Climate change is already increasing temperatures in the U.S. and globally. The Intergovernmental Panel on Climate Change (IPCC) has determined that it is very likely (90 to $100 \%$ probability) that there has been an increase in the number of warm days and nights globally since 1950 and likely (>66\% probability and less than $90 \%$ ) that these increases have been seen in North America. The IPCC also projects that it is very likely that the length, frequency, and intensity of heat waves will increase throughout the 21 st century with 1 -in-20 year hottest day events likely to become 1 -in- 2 
year events in North America (IPCC, 2012). Numerous studies have shown that increased temperatures during heat waves are directly related to increased mortality (Figure 17).

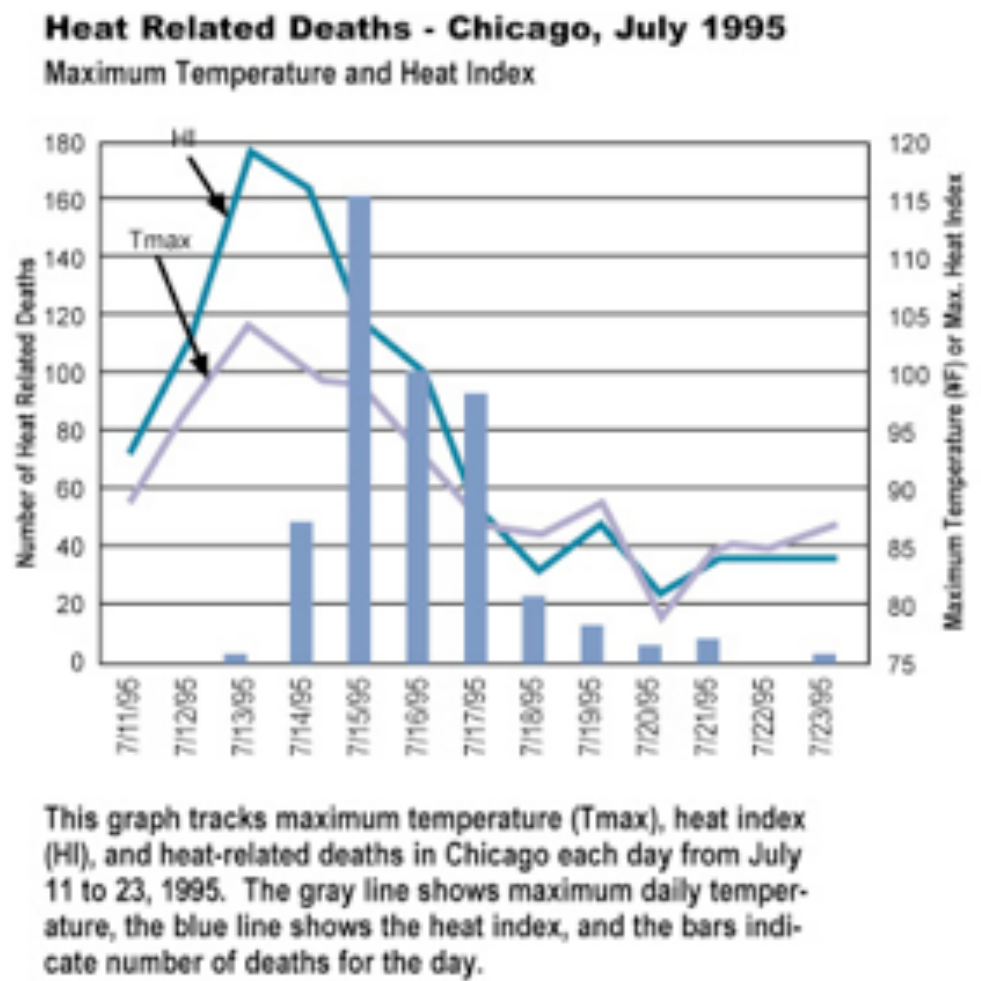

Figure 17. Heat-related deaths during the July 1995 heat wave in Chicago. Source: Semenza J.C. et al., 1996)

Health indicators are quantitative, summary measures that are used to track changes in conditions by person, place, and time (English et al., 2009). Attributes for ideal indicators include easy availability of high quality data, public health importance of the condition, and ease of communication. For human health impacts related to climate change, one measure that meets all of these criteria is heat-related mortality. The source for a heat-related mortality indicator is death certificate data compiled by CDC's National Center for Health Statistics, which is easily accessible and relatively timely (4 year lag). The measure is of public health importance since more than 600 people die each year from heat and in the U.S. and heat-related mortality rises dramatically during an extreme heat event, such as Chicago in 1995 or the European heat wave of 2003. The importance of this indicator has been shown to be easily communicated to the public and stakeholders by the media and governmental agencies and the measure is directly related to rising temperatures and extreme heat events, current and future consequences of climate change that have been identified as very likely by the IPCC.

As a measure of the overall public health impact of extreme heat events, heat-related mortality has limitations. The measure accounts for only those deaths with a "heat-related" coding on the death certificate. It has been well documented that many deaths associated with extreme heat are not identified as such by the medical examiner and are not correctly coded on the death certificate. However, heat-related mortality is an excellent indicator to identify increasing vulnerability to climate change-related extreme heat for populations and geographic areas and to track trends over 
time for human health impacts related to a changing climate. In addition, this measure is currently tracked annually for all states by CDC's National Environmental Public Health Tracking Program.

\subsubsection{Residential Energy Demand Temperature Index (REDTI).}

This index was established based upon research that indicates residential energy demand is highly correlated with temperature and more specifically with the accumulation of heating and cooling degree days (Diaz and Quayle, 1980). Because of this strong relationship, seasonal changes in the REDTI can provide a good indication of the nation's fluctuating energy demands. The REDTI is an example of an indicator that is a transformation of underlying climate data (spatial patterns of degree-day information derived from temperature observations), combined with socioeconomic data (spatial patterns of population density) to generate a nationally relevant index (residential temperature demand). Notably, the REDTI does not attempt to model total energy demand, because commercial and industrial demand is less correlated with degree-days.

\subsubsection{Social Vulnerability Index}

The Social Vulnerability Index (SoVI) is a composite index used to quantify spatial and temporal variations in the relative levels of social vulnerability to hazards. Social vulnerability is the inability of an individual to respond given a disaster, often described given certain demographic information (Cutter et al., 2003). The SoVI methodology is also used to examine differential disaster recovery and to model scenarios of potential future vulnerabilities. Based on the premise that social vulnerability to environmental hazards is multidimensional and dynamic, SoVI provides a comparative metric that can be applied to specific exposure units of interest such as counties, cities, census tracts, or census block groups located in climate-sensitive regions (e.g., coastal, riverine, or dryland areas). SoVI calculations combine hazard event frequency and economic loss data for specific hazard types or by specific time periods for multiple hazards. Time-series maps of SoVI results help reveal patterns of geographic variation in social vulnerability to hazards and disaster recovery.

Originally developed by Cutter et al. (2003), SoVI extends Cutter's (2006) hazards-of-place model of vulnerability, which integrates physical and social factors. The SoVI approach recognizes that the ability of communities and individuals to prepare for, respond to, cope with, recover from, and adapt to environmental hazards is influenced by social, economic, demographic, built environment, and housing characteristics. It has since been applied in a wide variety of contexts.

The first version of the SoVI employed 42 socioeconomic, demographic, and built environment variables, normalized to a fixed scale (percentages, per capita, or per square mile), to examine social vulnerability for all 3,141 U.S. counties in 1990. Eleven components-encompassing personal wealth, age, density of the built environment, single-sector economic dependence, housing stock and tenancy, race, ethnicity, occupation, and infrastructure dependence-were selected by performing a principal component analysis (PCA) and equally weighted in the analysis. These key factors of vulnerability explained about $76 \%$ of the total variation among U.S. counties. Subsequent SoVI calculations for the U.S. resulted in 11 to 12 components explaining $73 \%$ to $78 \%$ of the overall variation among U.S. counties in 1960, 1970, 1980, 1990, and 2000 (Cutter and Finch, 2008). The current version of the SoVI for U.S. counties synthesizes 32 independent variables derived from the research literature on hazard impacts and disaster preparedness, response, and recovery. The data are standardized and, using a PCA, reduced into a smaller set of key factors of vulnerability. These key components are summed to arrive at a single numerical value that represents the social vulnerability for each county, and these composite scores are 
displayed in relation to each other. Maps and data are available at the University of South Carolina's Hazards and Vulnerability Research Institute (HVRI; HVRI, 2012).

For the United States, SoVI has been calculated at the county, city, census tract, and census block group levels (Cutter and Finch, 2008). The data used to construct the SoVI for the U.S. are drawn from the U.S. Census Bureau and other national data sources. Cutter and Emrich (2010) applied SoVI to examine climate change-related hazards in the 13-state region of the U.S. Southeast (Alabama, Arkansas, Florida, Georgia, Kentucky, Louisiana, Maryland, Mississippi, North Carolina, South Carolina, Tennessee, Texas, and Virginia), which encompasses roughly $80 \%$ of all U.S. counties characterized by persistent poverty (Oxfam America 2009). This project (SoVI-SE) used 32 variables to define the multiple dimensions of vulnerability. Wealth, age, race, gender, ethnicity, rural farm population, special needs populations, and employment status accounted for most of the variation in social vulnerability. Several studies have utilized SoVI to investigate social vulnerability to hurricane-related hazards in the U.S. Gulf Coast region as a whole and in its subregions (e.g., Cutter et al., 2006; Myers et al., 2008; Finch et al., 2010). Schmidtlein et al. (2008) assessed the sensitivity of the SoVI by studying the impacts of changes in scale, changes in variable selection, and differences in geographic context. They applied SoVI at the census tract level to the cities of Charleston, Los Angeles, and New Orleans and found the SoVI algorithm to be fairly robust to minor changes in variable selection and to downscaling from the county to census tract level. However, the algorithm's sensitivity to changes in index construction varied across study areas. Adaptations of the SoVI approach have been applied in a number of contexts outside the U.S. including areas of Romania (Armas, 2008), Austria (Fuchs, 2009), Germany (Fekete, 2009), Portugal (Mendes, 2009), and Norway (Holand et al., 2011). It has also been adapted to study vulnerability to environmental hazards in the Ciudad Juárez (Mexico)-EI Paso (USA) metropolis (Collins et al., 2009). Additional examples of SoVI applications are listed at: http://webra.cas.sc.edu/hvri/products/soviapplications.aspx

As with many other indices, assessment of the conceptual, theoretical, and methodological validity of the SoVI remains a challenge. Data availability is another important constraint. Future work should continue to address the various subjective decisions made in the index construction process and to explore methodologies for determining relative weights. Past efforts have lacked a sufficient theoretical basis for making reliable judgments about the relative importance of index components, and have therefore weighted factors equally to arrive at composite SoVI scores.

\subsection{Adaptation and Mitigation Responses}

Although there are many examples of indicators in each of the previous categories, there is a paucity of them for adaptation and mitigation responses. The physical aspects of mitigation responses could be captured in indicators of greenhouse gas emissions, if they are tracked over time. But indicators of adaptation responses, either in terms of preparedness or in terms of responses to events or climate impacts, are significantly lacking, and will require research to identify. 


\section{Research Agenda to Improve and Sustain the National Climate Assessment Indicator System}

The need to improve both the overall indicator system and specific indicators in the system will require continued research efforts aimed at improving the scientific validity, utility, and efficiency of the indicator system and its components. For example, it may be possible to develop and apply new analysis or sampling methods that reduce lags between data collection and indicator delivery, improve the spatial and temporal representation of indicators, and/or reduce the costs of indicator production. For some sectors and impacts, basic data at the desired spatial resolution and frequency may not exist; research may be needed to develop efficient and accurate methods for data collection or for deriving or inferring needed data from other sources. In other cases, data may be available from multiple sources, necessitating research to improve consistency over space and continuity over time of derived indicators. In the arena of vulnerability and adaptation to climate change, scientific research on the nature of the physical and societal processes that lead to higher or lower vulnerability and that affect adaptation options and costs is still ongoing, suggesting the need to continually refine and improve indicators based on recent research results. It may also be important to identify and develop a range of "leading" indicators that can provide information on a time frame useful for certain types of decision making, such as disaster preparedness efforts.

The Indicator System to be developed in support of the NCA and U.S. Global Change Research Program must have the flexibility to evolve into the future. The need for evolution comes from several different directions. First, we expect that interest in indicators will grow in the future as expanded use of current and newly developed ones by an ever-widening group of users raises the visibility of the NCA indicators and the desire of potential users to have access to indicators most relevant to them. Second, as the available indicators are increasingly used, there will be valuable "lessons learned" about both the nature and use of the indicators that may point the direction for changes in current and new indicators into the future. Third, evolution will be required because of changes that take place in the observing systems that underpin the indicators; these changes may be due to year-to-year evolution of observing systems (e.g., gain and/or loss of observing stations, replacement of one generation of observing instrumentation with another) or the models that are involved in their generation. Fourth, advancing scientific capability (e.g., improved retrieval algorithms for remote sensing derived products) may suggest improvements that could be incorporated into the system that produces the indicators. The last three of these reasons all rely on continuing scientific research to enable the evolution of the Indicator System.

Changes in the indicator system are not necessarily easily made, however. Since many of the indicators are (or will be) produced by institutions different from those that constitute their major users, there will need to be a well-understood process to promote a dialogue in which the desires of the indicator users and the interests and capabilities of the indicator providers can be communicated to each other. When the need for new indicators is established, the users and providers of potential indicators must work to identify the characteristics of the new indicators, recognizing that in many cases, the observational information that is most easily obtained (or may be the only obtainable observational data) is not precisely that which the users desire, while the specific information that the users desire is not (and, for all practical purposes, may never be) directly available (either at all or at the desired spatial and/or temporal resolution) from the providers because of fundamental limitations of observational and/or model capability. 
Just as important as identifying potential new indicators, though, is the need to sustain indicators that have proven to be important and useful. Many indicators will depend on research programs in government agencies and universities for their underlying data, and ensuring that those data are sustained can be difficult for non-operational programs. This is a challenge that the NCA indicator system will have to address.

\subsection{Gap Analysis}

The NCA Indicator System should include a process for continual "gap analysis," i.e., ongoing efforts to identify critical gaps in data and information related to climate change impacts, adaptation, vulnerability, and mitigation and develop approaches and sources of data to fill these gaps as appropriate. For example, changes in climate-related extremes may lead to changes in both the magnitude and distribution of disaster losses from drought, floods, wildfires, severe storms, hail, lightning, landslides, and other hazards, including both direct and indirect losses. In many cases, these hazards are interrelated and may combine to increase overall damages, as in the case of drought leading to increased risk of wildfires, which in turn may lead to subsequent flooding and landslides. Indirect losses such as business interruption may also meet or exceed direct damages. Research is needed to improve methods of estimating both direct and indirect impacts for a range of potential climate phenomena, including both monetary and nonmonetary impacts and distributional effects. Also, as we improve our understanding there may be emerging issues that the indicator system may want to address to be responsive to the needs of decision makers.

Similarly, climate change may affect human welfare and activities in ways that are difficult to predict in advance. For example, as ecosystems respond to changes in seasonality and extremes, human exposure to disease pathogens, vectors, and related environmental conditions may evolve over time, potentially affecting morbidity and mortality in new ways. This may necessitate modifying current health indicators or adding new indicators in order to ensure appropriate characterization of climate-health interactions.

\subsection{Indicator Evaluation}

As the NCA Indicator System is established, and to help provide a rigorous framework for consideration of possible modifications and augmentations to the available suite of indicators, it is crucial that there be a well-established process for objective evaluation of the available indicators. Criteria for such an evaluation may include:

- the scientific rigor of the indicator, including the quality, traceability, reproducibility, and comprehensiveness (e.g., spatial coverage, temporal sampling) of the observational data, retrieval algorithm, and model calculation that contribute to its development;

- the degree of use of the indicator, including the nature of the users, and the way in which it is being used; and

- assessment of the need for evolution of the indicator on the basis of user and/or provider

feedback, including that which is both currently feasible as well as important for the future.

Best practice in the development of monitoring systems suggests the need to define an evaluation process and criteria in advance of implementation. In light of the potential complexity and unique aspects of the NCA Indicator System, focused research on how best to evaluate the system may be needed. For example, this might involve developing baseline information regarding the knowledge and practices of the target user communities, to enable future assessment of the effectiveness and impact of the indicator system. 
As the need to evolve the Indicator System is recognized, numerous implementation issues arise which must be addressed if that evolution is to take place efficiently and effectively. Appropriate interaction mechanisms must exist to connect the indicator providers (including both current and potential new indicator providers) and users, as well as to enable orderly transitions so that indicator users are able to plan for, respond to, and document the impacts of changes in relevant indicators, as well as to retire indicators when appropriate. Open discussion can inform decisions such as how to deal with multiple related indicators that address similar issues (including, for instance, how to assess relative merits through intercomparison efforts and, when appropriate, achieve a community standard to limit the number of related indicators being produced in the future). Decisions must be made about how to maintain the traceability of indicators that have been supplanted by newer ones either through reprocessing or replacement, and how to prioritize among the many possible changes to the suite of indicators that constitute the Indicator System.

\subsection{Uncertainties and Major Existing Gaps}

How uncertainties in underlying knowledge and in underlying data will be treated in the NCA indicators is an important issue that will require further research. Uncertainties in underlying knowledge of the physical climate system, processes that control emissions and sinks, processes that control vulnerability to impacts all evolve over time, and can obviously affect the derivation and/or construction of indicators. For example, NOAA's Aggregate Greenhouse Gas Index (AGGI) must incorporate new information on greenhouse gas lifetimes in the atmosphere or their radiative properties. Similarly, ecological indicators must adapt to new understanding of the sensitivity of important phenomena, such as wildfire and pests, to climate variability and change, and to the availability of entirely new data sets, such as the plethora of remotely sensed data that have become available over the past decade. Uncertainties in measurements (or models) that underlie indicators should be rigorously identified and quantified where possible, so that baselines can be established with known certainty, and therefore the indicators can be used to detect trends.

Some of the more pressing research needs, however, come from those parts of the framework in which our overall understanding reflects either a lack of research effort, or simply the difficulty of creating a quantitative understanding of processes. These criteria are especially important for indicators of human well-being, health, vulnerability, and adaptation and mitigation responses.

The derivation of societal indicators is especially challenging. There has been a long history in the use of indicators to help to understand humans and their communities, going back at least to Aristotle's empirical work comparing Greek city states. From the 1960s onwards, American scholars and policy makers have devoted efforts to develop social indicators to help them measure the wellbeing of people and their communities. More recently, scholars have combined different data sources to create indicators of complex, multi-dimensional concepts such as vulnerability to climate change and to other environmental threats (e.g., Moss et al., 2001; Eriksen and Kelly, 2007), sustainability of human or natural systems (e.g., NRC, 1999; NRC, 2010b), and resilience (e.g., Cutter et al., 2010).

Although the amount of data about humans and their conditions has increased exponentially since the 1960s and sophisticated methods for combining datasets have emerged, the consensus among indicator scholars is that much important work on societal indicators remains to be done. One significant limitation is that data are missing for many aspects of social systems. Either data were not collected in the past or the data are exceedingly crude, e.g., one observation for every 10 years 
from the decadal census. A second problem is that what is easy to measure is not necessarily what one would like to know. For example, measuring the distribution of years of schooling in a community is easy, but measuring a community's capacities for problem-solving is much more difficult. Finally, much work remains to be done to integrate social data with data from the natural sciences.

A suite of indicators that allows monitoring the effects of climate change and societal response to it must take account of changes in human well-being. Traditionally, indirect measures of human well-being, such as income or gross domestic product have dominated environmental analysis. However, a growing body of evidence demonstrates that direct measures of human well-being can be valuable complements to traditional indirect measures such as income or gross domestic product (Frey, 2008). For example, measures of life satisfaction and happiness are increasingly used to inform policy choices (Commission on the Measurement of Economic Performance and Social Progress 2009; Diener et al. 2008; Diener et al. 2009; Stiglitz et al. 2009; U.K. Department for Environment 2011). A set of techniques to use life satisfaction for environmental valuation is being explored (Frey et al. 2009; Luechinger and Rashsky 2009; Welsch and Kühling 2009) as are studies relating life satisfaction to environmental quality (MacKeron and Mourato 2009). The methodology for measuring life satisfaction has become quite sophisticated as has our understanding of the effects of social structure and life events on it (Frey 2008; Kahneman and Krueger 2006; Kahneman et al. 1999; Krueger 2009). Recently efforts have directly compared subjective well-being to stress placed on the environment (Engelbrecht 2009; New Economics Foundation 2009).

Efforts to assess the impacts of climate change can make effective use of life satisfaction measures. While it is necessary to conduct a survey to collect data on life satisfaction, the marginal cost of including life satisfaction in a multi-purpose survey is modest, especially given increasingly effective and efficient internet-based survey methods. In assessing the ongoing impacts of climate change and of efforts to adapt to and mitigate climate change, subjective well-being measures such as life satisfaction provide a useful addition to standard assessments of income and economic activity. They may prove more sensitive than these measures to climate change. It is well established that the relationship between income or GDP and life satisfaction is strong only across the range from relatively low income/ GDP per capita to moderate income/ GDP per capita. After moderate levels of affluence are reached, these objective measures of well-being have only modest relationship to subjective well-being. Thus subjective measures may detect important wellbeing changes that are not detected with objective measures and vice-versa. Research linking subjective well-being to climate change is still in an early stage, but holds considerable promise Efforts to apply this approach to climate change are emerging (Ambrey and Fleming 2011; Carroll et al. 2009; Rehdanz and Maddison 2005).

The derivation of indices for adaptation and mitigation responses is requires further development. There are conceptual issues, such as the difference between preparedness and responses, and ensuring these are represented well is a major challenge. But a primary reason for the lack of indicators in these categories is that the underlying research on adaptation itself has not been done in a way that would catalyze the development of indicators. For mitigation, there is a long tradition of research, but little of that has been targeted towards the development of a systematic set of indicators except for greenhouse gas emissions and atmospheric concentrations. In both these cases, the USGCRP research program will need to provide a research foundation that the ongoing assessment process can build on for the identification of appropriate indicators. 


\section{Concluding Remarks}

The continued need for a comprehensive set of indicators in the ongoing process of the National Climate Assessment will be a function of both the variable and changing climate and its impacts, and also the need to understand the degree to which the Nation is preparing to respond to those changes. Previous indicator efforts have shown that not all environmental indicators have sufficient data available, or sufficiently robust methods, that they can be calculated on a national basis. Nationally relevant indicators will also not always be appropriate in all regions of the country, since the manifestations of climate change and its impacts are so variable, and since the conditions that confer resiliency vary from place to place. Thus, indicators must have sufficient data and established methodology, and will be most useful if they can operate across scales - e.g., calculated locally but able to be aggregated to state, regional or national levels, or vice versa.

In this report, the Working Group has identified an overall framework within which an end-to-end system of indicators can be developed as part of the ongoing process of the NCA. Within that framework, and using the existing literature and workshops conducted specifically for the NCA, we have been able to demonstrate that there are examples of indicators, the programs that have been set up to derive and report them, and the foundational monitoring and observation programs on which they are based. There are, however, major gaps in some areas, especially those related to societal indicators, human well-being, and health. Of particular concern are indicators that are relevant to understanding the nation's progress on climate adaptation, and ensuring that what is already known about greenhouse gas mitigation can be captured in an indicator context.

Finally, although there are already many examples of programs and indicators, their purpose and relevance to decision-making processes are not always clear. Many existing indicators (and the programs that support them) for climate-related information have been created primarily for educational, research, and informational purposes. While some of the climate-related indicators for the physical climate system are integrated into operational decision-making, the majority of those examined to date have been created to illuminate scientific issues or provide information more generally. Ecosystem indicators, too, have varied between being largely informational (e.g. the Heinz Center State of the Nation's Ecosystem) and being part of a resource management process (USFS forest sustainability indicators). Understanding the desires of different stakeholder communities, and their needs either for operational decision-making, policy-making, scientific research, or public information remains a serious strategic challenge for the NCA.

\section{Acknowledgements}

The authors wish to acknowledge support of the National Oceanic and Atmospheric Administration (NOAA), National Aeronautics and Space Administration (NASA), Environmental Protection Agency (EPA), Columbia University, Department of Interior (DOI) U.S. Geological Survey (USGS), U.S. Department of Agriculture (USDA), Department of Energy (DOE), and National Science Foundation (NSF). This work was improved by the reviews provided by Bilal Ayyub (University of Maryland), William Emanuel (Joint Global Change Research Institute and USGCRP NCA), Paul English (California Department of Public Health), John Hall (Department of Defense), Peter Murdoch (DOI, USGS), Gregory Pederson (DOI, USGS), Robin O'Malley (DOI, USGS), Robert B. Richardson (Michigan State University), David A. Robinson (Rutgers University), and Dave White (Arizona State University). 


\section{References}

Ambrey, Christopher L and Christopher M Fleming. 2011. "The influence of the natural environment and climate on life satisfaction in Australia." in 55th Annual AARES National Conference. Melbourne.

Arctic Sea Ice News and Analysis, National Snow and Ice Data Center (NSIDC): http://nsidc.org/arcticeaicenews/

Arctic Sea Ice Volume, Univ. Washington Polar Science Center:

http://psc.apl.washington.edu/wordpress/research/projects/arctic-sea-ice-volume-anomaly/

Armaş, I. (2008) Social vulnerability and seismic risk perception. Case study: the historic center of the Bucharest Municipality/Romania. Natural Hazards, 47, 397-410.

Ayyub, B. M., 2003 ( ${ }^{\text {nd }}$ ed. Expected 2013). Risk analysis in engineering and economics, Chapman Hall/CRC Press, FL.

Ayyub, B. M., and Klir, G., 2006. Uncertainty modeling and analysis in engineering and the sciences, Chapman Hall/CRC Press, FL.

Ayyub, B. M., 2001. Elicitation of expert opinions for uncertainty and risks, CRC Press, FL.

Balk, D., U. Deichmann, G. Yetman, F. Pozzi, S.I. Hay, and A. Nelson. 2006. Determining global population distribution: Methods, applications, and data. Advances in Parasitology 62: 119-156.

Bureau of Economic Analysis (BEA). http://www.bea.gov/. Accessed February 26, 2012.

Bureau of Labor Statistics (BLS). http://www.bls.gov/cpi/cpiovrvw.htm. Accessed February 26, 2012.

Carroll, Nick, Paul Frijters, and Michael A Shields. 2009. "Quantifying the costs of drought: new evidence from life satisfaction data." Population Economics 22:445-461.

Centers for Disease Control (CDC). http://www.cdc.gov/nchs/nvss.htm. Accessed February 26, 2012.

Centers for Disease Control (CDC). 2006. Heat-related deaths - U.S., 1999-2003. MMWR 2006; 55:796-8.

Committee on Environment and Natural Resources (CENR). 1997. Integrating the Nation's environmental monitoring and research networks and program: A proposed framework.

Washington, DC: Committee on Environment and Natural Resources, Subcommittee on Ecological Systems.

Collins, T. W., S. E. Grineski \& M. d. L. R. Aguilar (2009) Vulnerability to environmental hazards in the Ciudad Juárez (Mexico)-El Paso (USA) metropolis: A model for spatial risk assessment in transnational context. Applied Geography, 29, 448-461. 
Commission on the Measurement of Economic Performance and Social Progress. 2009. "Report by the Commission on the Measurement of Economic Performance and Social Progress." Commission on the Measurement of Economic Performance and Social Progress, Paris, France.

Cutter, S. L., \& C. Finch (2008). Temporal and spatial changes in social vulnerability to natural hazards. Proceedings of the National Academy of Sciences, 105(7), 2301-2306.

Cutter, S. L., B. J. Boruff \& W. L. Shirley (2003) Social vulnerability to environmental hazards. Social Science Quarterly, 84(2), 242-261.

Cutter, S. L., C. T. Emrich, J. T. Mitchell, B. J. Boruff, M. Gall, M. C. Schmidtlein, C. G. Burton \& G. Melton (2006) The Long Road Home: Race, Class, and Recovery from Hurricane Katrina. Environment: Science and Policy for Sustainable Development, 48, 8-20.

Cutter, S., C.G. Burton, and C.T. Emrich. 2010. Disaster resilience indicators for benchmarking baseline conditions. Journal of Homeland Security and Emergency Management 7: Article 51.

Diaz, H.F., and R.G. Quayle, 1980: Heating Degree Day Data Applied to Residential Heating Energy Consumption. Journal of Applied Meteorology, 3, 241-246.

Diener, Ed, Richard E Lucas, and Ulrich Schimmack. 2008. "National Accounts of Well-Being." Oxford: Oxford University Press.

Diener, Ed, Richard Lucas, Ulrich Schimmack, and John Helliwell. 2009. "Well-being for public policy." Oxford: Oxford University Press.

Doll, Christopher N.H. 2008. CIESIN Thematic Guide to Night-time Light Remote Sensing and its Applications. Palisades NY: NASA Socioeconomic Data and Applications Center. http://sedac.ciesin.org/tg/guide frame.jsp?rd=NL\&ds=1. Accessed February 26, 2012.

Engelbrecht, Hans-Jürgen. 2009. "Natural capital, subjective well-being, and the new welfare economics of sustainability: Some evidence from cross-country regressions." Ecological Economics 69:380-388.

English PB, Sinclair AH, Ross Z, Anderson H, et al. 2009. Environmental health indicators for climate change for the US: Findings from the State Environmental Health Indicator Collaborative. Environ Health Perspect; 117:1673-1681.

Eriksen, S., and R. Kelly. 2007. Developing credible vulnerability indicators for climate change adaptation policy assessment. Mitigation and Adaptation Strategies for Global Change 12:495-524.

Fekete, A. (2009) Validation of a social vulnerability index in context to river-floods in Germany. Natural Hazards and Earth System Sciences, 9, 393-403.

Frey, Bruno S. 2008. Happiness: A Revolution in Economics. Cambridge, Massachusetts: The MIT Press. 
Frey, Bruno S, Simon Luechinger, and Alois Stutzer. 2009. "The Life Satisfaction Approach to Environmental Valuation." CESifo, Munich, Germany.

Finch, C., C. T. Emrich \& S. L. Cutter (2010) Disaster disparities and differential recovery in New Orleans. Population and Environment, 31, 179-202.

Fuchs, S. (2009) Susceptibility versus resilience to mountain hazards in Austria - paradigms of vulnerability revisited, Natural Hazards and Earth System Sciences, 9, 337-352.

General Social Survey, National Opinion Research Center (NORC).

http://www3.norc.org/GSS+Website Accessed February 29, 2012.

Gleason, Karin L., Jay H. Lawrimore, David H. Levinson, Thomas R. Karl, David J. Karoly, 2008: A Revised U.S. Climate Extremes Index. J. Climate, 21, 2124-2137.

Global Climate Observing System (GCOS), 2003: The second report on the adequacy of the Global Observing Systems for Climate in support of the UNFCCC. GCOS-82, WMO/TD No. 1143, 74 pp. [Available online at http://www.wmo.int/pages/prog/gcos/Publications/gcos-82_2AR.pdf.]

Grasso, V.F., 2009: Early Warning Systems: State of the Art Analysis and Future Directions. UNEP Draft Report.

Hazards and Vulnerability Research Institute (HVRI). Social Vulnerability Index for the United States. University of South Carolina. http://www.sovius.org

Hayes, Michael, Mark Svoboda, Nicole Wall, and Melissa Widhalm, 2011: The Lincoln Declaration on Drought Indices: Universal Meteorological Drought Index Recommended. Bull. Amer. Meteor. Soc., 92, 485-488. doi: 10.1175/2010BAMS3103.1

Heim, Richard R., 2002: A review of twentieth-century drought indices used in the United States. Bull. Amer. Meteor. Soc., 83, 1149-1165.

Heinz Center. 2002. State of the Nation's Ecosystems 2002. Cambridge Press. Washington, DC.

Heinz Center. 2004. Filling the Gaps: Priority Data Needs and Key Management Challenges for National Reporting on Ecosystem Condition. The H. John Heinz III Center for Science, Economics, and the Environment. Washington, DC.

Heinz Center. 2006. Filling the Gaps: Priority Data Needs and Key Management Challenges for National Reporting on Ecosystem Condition. A Report of the Heinz Center's State of the Nation's Ecosystems Project. The H. John Heinz III Center for Science, Economics, and the Environment.

Heinz Center. 2008a. State of the Nation's Ecosystems 2008. The H. John Heinz III Center for Science, Economics, and the Environment. Washington, DC.

Heinz Center. 2008b. Environmental Information: A Road Map to the Future. The H. John Heinz III Center for Science, Economics, and the Environment. Washington, DC. 
Heinz Center. 2008c. Landscape Pattern Indicators for the Nation. The H. John Heinz III Center for Science, Economics, and the Environment. Washington, DC.

Heinz Center. 2010. Indicators of Ecological Effects of Air Quality. The H. John Heinz III Center for Science, Economics, and the Environment. Washington, DC.

Henderson, Vernon; Storeygard, Adam and Weil, David Nathan: Measuring Economic Growth from Outer Space, American Economic Review (forthcoming, 2012).

Holand, I. S., P. Lujala \& J. K. Rød (2011) Social vulnerability assessment for Norway: A quantitative approach. Norsk Geografisk Tidsskrift - Norwegian Journal of Geography, 65, 1-17.

ICESat sea ice thickness, NASA JPL: http://rkwok.jpl.nasa.gov/icesat/

Ice mass balance buoys, U.S. Army CRREL: http://imb.crrel.usace.army.mil/

IPCC, 2012: Summary for Policymakers. In: Managing the Risks of Extreme Events and Disasters to Advance Climate Change Adaptation. A Special Report of Working Group 1 and 11 of the IPCC. Cambridge University Press, Cambridge, UK, pp. 1-19.

Jones, K.B., H. Bogena, H. Vereecken, and J.F. Weltzin. 2010. Design and Importance of Multitiered Ecological Monitoring Networks. Pages 355-374 in F. Müller et al. (eds.), Long-Term Ecological Research, Springer Science+Business Media B.V. DOI 10.1007/978-90-481-8782-9_25

Kahneman, Daniel and Alan B Krueger. 2006. "Developments in the Measurement of Subjective Well-Being." Journal of Economic Perspectives 20:3-24.

Kahneman, Daniel, Ed Diener, and Norbert Schwarz. 1999. "Well-Being: The Foundations of Hedonic Psychology." New York: Russell Sage Foundation.

Karl TR., JM Melillo, TC Peterson, eds. 2009. Global Climate Change Impacts in the United States. Cambridge Univ. Press: New York.

Krueger, Alan B. 2009. "Measuring the Subjective Well-Being of Nations." Chicago: University of Chicago Press.

Luber G, McGeehin M. Climate change and extreme heat events. 2008. Am J Prev Med; 35(5):429-435.

Luechinger, Simon and Paul A Rashsky. 2009. "Valuing flood disasters using the life satisfaction approach." Journal of Public Economics 93:620-633.

MacKeron, George and Susana Mourato. 2009. "Life satisfaction and air quality in London." Ecological Economics 58:1441-1453.

McGeehin MA, Qualters JR, Niskar AS. National Environmental Public Health Tracking Program: bridging the information gap. Environ Health Perspect. 2004; 112(14): 1409-1413. 
Mendes, J. M. d. O. (2009) Social vulnerability indexes as planning tools: beyond the preparedness paradigm. Journal of Risk Research, 12, 43-58.

Menne, M.J., and C.N. Williams, Jr., 2009: Homogenization of temperature series via pairwise comparisons. J. Climate, 22, 1700-1717.

Myers, C., T. Slack \& J. Singelmann (2008) Social vulnerability and migration in the wake of disaster: the case of Hurricanes Katrina and Rita. Population and Environment, 29, 271-291.

Moss, R., A.L. Brenkert, and E.L. Malone. 2001. Vulnerability to Climate Change: A Quantitative Approach. PNNL-SA-33642. Pacific Northwest National Laboratory.

National Integrated Drought Information System Implementation Plan: A Pathway for National Resilience, 2007: http://www.drought.gov/portal/server.pt/community/what_is_nidis/207

National Oceanic and Atmospheric Administration. National Geophysical Data Center (NGDC). http://www.ngdc.noaa.gov/dmsp/download.html. Accessed February 26, 2012.

National Research Council (NRC). 1999. Our Common Journey: a Transition toward Sustainability. Washington DC: National

Academies Press.

National Research Council (NRC). 2000. Ecological Indicators for the Nation. National Academy Press. Washington, DC.

National Research Council (NRC). 2004. Climate Data Records from Environmental Satellites: Interim Report. National Academy Press. Washington, DC.

National Research Council (NRC). 2010a. Advancing the Science of Climate Change. Washington, DC: National Research Council, The National Academies Press.

National Research Council (NRC). 2010b. Monitoring Climate Change Impacts: Metrics at the Intersection of the Human and Earth Systems. Washington, DC: National Research Council, The National Academies Press.

New Economics Foundation. 2009. The Happy Planet Index. London: New Economics Foundation.

Office of Science and Technology Policy (OSTP). 2010. Achieving and Sustaining Earth Observations: A Preliminary Plan Based on a Strategic Assessment by the U.S. Group on Earth Observations. OSTP, September 2010.

Oxfam America. (2009). Exposed: social vulnerability and climate change in the U.S. Southeast. Boston, MA: Oxfam America Inc. http://www.oxfamamerica.org/files/Exposed-Social-Vulnerabilityand-Climate-Change-in-the-US-Southeast.pdf

Parmesan, C. 2007. Influences of species, latitudes and methodologies on estimates of phenological response to global warming. Global Change Biology 13:1860-1872. 
Rehdanz, Katrin and David Maddison. 2005. "Climate and happiness." Ecological Economics 52:111-125.

Roper Center for Public Opinion Research. http://www.ropercenter.uconn.edu/. Accessed February 26, 2012.

Rosenzweig C et al. 2007. Assessment of observed changes and responses in natural and managed systems. In ML Parry et al., eds. Climate Change 2007: Impacts,

Adaptation and Vulnerability. WG II, FAR, IPCC, Cambridge Univ. Press: New York.

Running, S.W., R.R. Nemani, F.A. Heinsch, M. Zhao, M. Reeves, H. Hashimoto. (2004) A

Continuous Satellite-Derived Measure of Global Terrestrial Primary Production. BioScience 54(6):547-560.

Sagarin, R. and A. Pauchard. (2009) Observational approaches in ecology open new ground in a changing world. Frontiers in Ecology and Environment 5:296

Sanderson, E.W., M. Jaiteh, M.A. Levy, K.H. Redford, A.V. Wannebo, and G. Woolmer. 2002. The Human Footprint and the Last of the Wild, BioScience 52, 10:891-904.

Schmidtlein, M. C., R. C. Deutsch, W. W. Piegorsch, S. L. Cutter (2008). A sensitivity analysis of the Social Vulnerability Index. Risk Analysis 28(4), 1099-1114.

Schwartz, M. D., R. Ahas, and A. Aasa. 2006. Onset of Spring Starting Earlier Across the Northern Hemisphere. Global Change Biology 12: 343-351.

Schwartz, M.D., J.L. Betancourt, and J.F. Weltzin. 2012. From Caprio's Lilacs to the USA National Phenology Network. Frontiers in Ecology and the Environment: invited manuscript in review.

Schwartz, M. D. and B. E. Reiter, 2000. Changes in North American Spring. International Journal of Climatology 20: 929-932.

Semenza J.C., Rubin C.H., Falter K.H., et al. 1996. Heat-related deaths during the July 1995 heat wave in Chicago. New England Journal of Medicine; 335:84-90.

Stiglitz, Joseph, Amartya Sen, and Jean-Paul Fitoussi. 2009. "The Measurement of Economic Performance and Social Progress Revisited." Commission on the Measurement of Economic Performance and Social Progress, Paris.

Svoboda, M., D. LeComte, M. Hayes, R. Heim, K. Gleason, J. Angel, B. Rippey, R. Tinker, M. Palecki, D. Stooksbury, D. Miskus, and S. Stephens, 2002. The Drought Monitor. Bull. Amer. Meteor. Soc., 83(8):1181-1190.

Teutsch SM. 2000. Consideration in planning a surveillance system. In: Principles and Practices of Public Health Surveillance (Teutsch SM, Churchill RE, eds.) New York: Oxford University Press, 17-29. 
Thomas, K.A., E.G. Denny, A.J. Miller-Rushing, T.M. Crimmins, and J.F. Weltzin. 2010. The National Phenology Monitoring System v0.1. USA-NPN Technical Series 2010-001.

http://www.usanpn.org/files/shared/files/Thomas_NPMSv0.1-FINAL.pdf Accessed on February 1, 2012.

U.K. Department for Environment, Food and Rural Affairs. 2011. " Life Satisfaction and Other Measures of Wellbeing in England, 2007-2011 " U.K. Department for Environment, Food and Rural Affairs, London.

U.S. Census Bureau. http://www.census.gov/history/www/through_the_decades/overview/. Accessed February 26, 2012.

U.S. Environmental Protection Agency (U.S. EPA). 2010. Climate Change Indicators in the United States. EPA 430-R-10-007, April 2010. http://epa.gov/climatechange/indicators.html

U.S. Environmental Protection Agency (U.S. EPA). 2011. Inventory of U.S. greenhouse gas emissions and sinks: 1990-2009. USEPA \#EPA 430-R-11-005.

www.epa.gov/climatechange/emissions/usinventoryreport.html

US Geological Survey (USGS). 2012. USGS Strategy Workshop for Fostering a Monitoring Framework. Report of a Workshop at USGS, 1-2 December 2011.

U.S. Global Change Research Program (USGCRP). 2011a. Ecosystem Responses to Climate Change: Selecting Indicators and Integrating Observational Networks. The United States National Climate Assessment, NCA Report Series, Volume 5a. USGCRP NCA Workshop Report. pp. 32.

U.S. Global Change Research Program (USGCRP). 2011b. Monitoring Climate Change and its Impacts: Physical Climate Indicators. The United States National Climate Assessment, NCA Report Series, Volume 5b. USGCRP NCA Workshop Report. pp. 32.

U.S. Global Change Research Program (USGCRP). 2012. Climate Change Impacts and Responses: Societal Indicators for the National Climate Assessment. The United States National Climate Assessment, NCA Report Series, Volume 5c. USGCRP NCA Workshop Report. pp. 122.

Vose, Russell S., 2005: Reference Station Networks for Monitoring Climatic Change in the Conterminous United States. J. Climate, 18, 5390-5395.

Welsch, Heinz and John Kühling. 2009. "Using Happiness Survey Data for Economic Valuation: Issues and Applications." Journal of Economic Surveys 23:385-406.

Wilhite, D. A., and M. H. Glantz. 1985. Understanding the drought phenomenon: The role of definitions. Water International 10, 111-120.

Wilhite, D. A., 2000: Drought as a natural hazard: Concepts and definitions. Drought: A Global Assessment, D. Wilhite, Ed., Vol. 1, 3-18. 
Zhao, M and S.W. Running. (2010). Drought induced reduction in global terrestrial net primary production from 2000 through 2009. Science 329:940-943. 


\section{Appendix}

\section{A. Examples of Federal Agency Monitoring Networks and Observation Systems}

\begin{tabular}{|c|c|}
\hline Agency Name & Programs that Directly Participate in the Activity \\
\hline $\begin{array}{l}\text { Department of Interior (DOI), } \\
\text { U.S. Geological Survey }\end{array}$ & $\begin{array}{l}\text { - Water Data for the Nation. Critical surface water, ground } \\
\text { - water, and water quality data. } \\
\text { National Streamflow Information Program. Long-term } \\
\text { stream flow information through a network of streamgages } \\
\text { throughout the U.S. } \\
\text { LANDSAT. Long-term moderate-resolution land remote } \\
\text { sensing data. }\end{array}$ \\
\hline $\begin{array}{l}\text { Department of Interior (DOI), } \\
\text { National Park Service (NPS) }\end{array}$ & $\begin{array}{l}\text { Inventory and Monitoring Program. A set of } 12 \text { "basic" } \\
\text { natural resource inventories (e.g., vegetation inventory, } \\
\text { species lists, species occurrence and distribution) } \\
\text { common to all parks with significant natural resources. }\end{array}$ \\
\hline $\begin{array}{l}\text { Department of Commerce } \\
\text { (DOC), National Oceanic and } \\
\text { Atmospheric Administration } \\
\text { (NOAA) }\end{array}$ & $\begin{array}{l}\text { - Climate Program Office (CPO), Climate Observation and } \\
\text { Monitoring (COM). Design, deploy, and sustain an } \\
\text { integrated global network of oceanic, atmospheric, and } \\
\text { Arctic observing instruments to produce continuous } \\
\text { records, as well as value-added products, of a number of } \\
\text { essential climate variability and change parameters. } \\
\text { - U.S. Climate Reference Network (CRN). Very-high quality } \\
\text { daily data since early 2000s explicitly designed to capture } \\
\text { climate-scale change and variability at the scale of the } \\
\text { United States. } \\
\text { U.S. Historical Climatology Network. High-quality } \\
\text { moderate sized data set of monthly averaged maximum, } \\
\text { minimum, and mean temperature and total monthly } \\
\text { precipitation developed to assist in the detection of } \\
\text { regional climate change. } \\
\text { National Climatic Data Center (NCDC). National and } \\
\text { global climate data sets on trends and anomalies of } \\
\text { weather and climate. } \\
\text { Geostationary Operational Environmental Satellites } \\
\text { (GOES). Imagery to identify severe weather, snow storms, } \\
\text { tropical storms and hurricanes and on-board sensors } \\
\text { detect cloud, land, and ocean temperatures, as well as } \\
\text { monitor activities of the sun. } \\
\text { Polar Operational Environmental Satellites (POES). } \\
\text { Weather analysis and forecasting, climate research and } \\
\text { prediction, global sea surface temperature measurements, } \\
\text { measurements of temperature and humidity of the } \\
\text { atmosphere, ocean dynamics research, volcanic eruption } \\
\text { monitoring, forest fire detection, and global vegetation }\end{array}$ \\
\hline
\end{tabular}




\begin{tabular}{|c|c|}
\hline & $\begin{array}{l}\text { analysis. } \\
\text { Ocean Surface Topography Mission (OSTM)/JASON-2. } \\
\text { Satellite altimetry data provides sea surface heights for } \\
\text { determining ocean circulation, climate change and sea- } \\
\text { level rise. } \\
\text { loint Polar Satellite System (JPSS). Weather-forecasting, } \\
\text { storm tracking, and climate-monitoring requirements to } \\
\text { improve and extend climate measurements for } 30 \\
\text { different Environmental Data Records of the atmosphere, } \\
\text { land, ocean, climate, and space environment. }\end{array}$ \\
\hline $\begin{array}{l}\text { Department of Commerce } \\
\text { (DOC), Census Bureau }\end{array}$ & 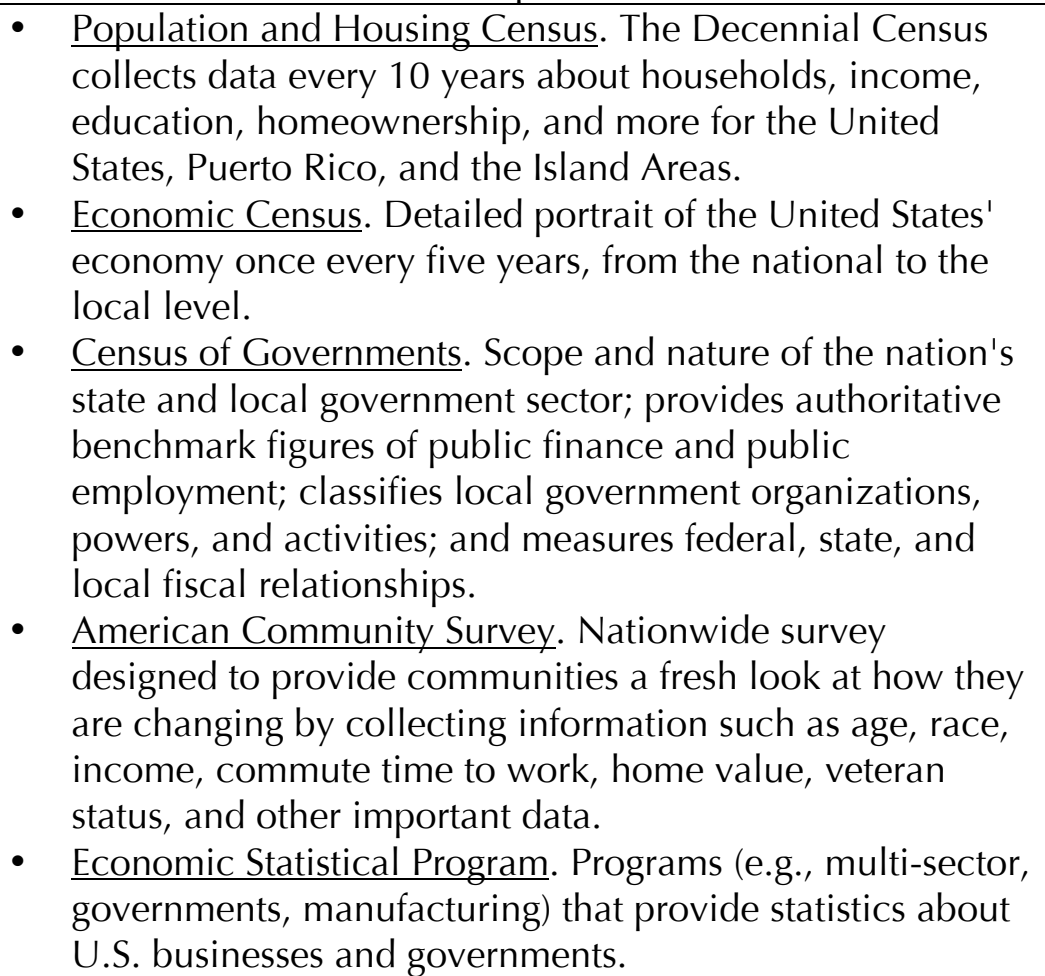 \\
\hline $\begin{array}{l}\text { U.S. Department of } \\
\text { Agriculture (USDA) }\end{array}$ & $\begin{array}{l}\text { - Census of Agriculture (NASS). The Census of Agriculture } \\
\text { is the leading source of facts and figures about American } \\
\text { agriculture. Conducted every five years, the Census } \\
\text { provides a detailed picture of U.S. farms and ranches and } \\
\text { the people who operate them. }\end{array}$ \\
\hline $\begin{array}{l}\text { U.S. Department of } \\
\text { Agriculture (USDA), National } \\
\text { Resources Conservation } \\
\text { Service (NRCS) }\end{array}$ & $\begin{array}{l}\text { National Resources Inventory (NRI) and Conservation } \\
\text { Effects Assessment Program (CEAP). The NRI is a } \\
\text { statistical survey of land use and natural resource } \\
\text { conditions and trends on U.S. non-Federal lands. This } \\
\text { data supports the CEAP, an effort to quantify the } \\
\text { environmental effects of conservation practices and } \\
\text { programs and develop the science base for managing the } \\
\text { agricultural landscape for environmental quality. } \\
\text { Soil Climate Analysis Network (SCAN). The Soil Climate } \\
\text { Analysis Network (SCAN) is network of over } 150 \text { stations } \\
\text { in } 39 \text { states that provide soil moisture and climate } \\
\text { information. }\end{array}$ \\
\hline
\end{tabular}




\begin{tabular}{|c|c|}
\hline & $\begin{array}{l}\text { - SNOTEL (SNOwpack TELemetry). Installation, operation, } \\
\text { and maintenance of an extensive, automated system to } \\
\text { collect snowpack and related climatic data in the Western } \\
\text { United States. }\end{array}$ \\
\hline $\begin{array}{l}\text { U.S. Department of } \\
\text { Agriculture (USDA), } \\
\text { Economic Research Service } \\
\text { (ERS) }\end{array}$ & $\begin{array}{l}\text { Agricultural Resource Management Survey (ARMS). } \\
\text { Economic information and research involving food, } \\
\text { farming, natural resources, and rural development. }\end{array}$ \\
\hline $\begin{array}{l}\text { U.S. Department of } \\
\text { Agriculture (USDA), Forest } \\
\text { Service (USFS) }\end{array}$ & $\begin{array}{l}\text { Forest Inventory and Assessment Program (FIA). The } \\
\text { national forest inventory, provides reports on status and } \\
\text { trends in forest area and location; in the species, size, and } \\
\text { health of trees; in total tree growth, mortality, and } \\
\text { removals by harvest; in wood production and utilization } \\
\text { rates by various products; and in forest land ownership. }\end{array}$ \\
\hline $\begin{array}{l}\text { U.S. Department of } \\
\text { Agriculture (USDA), } \\
\text { Agriculture Research Service } \\
\text { (ARS) }\end{array}$ & 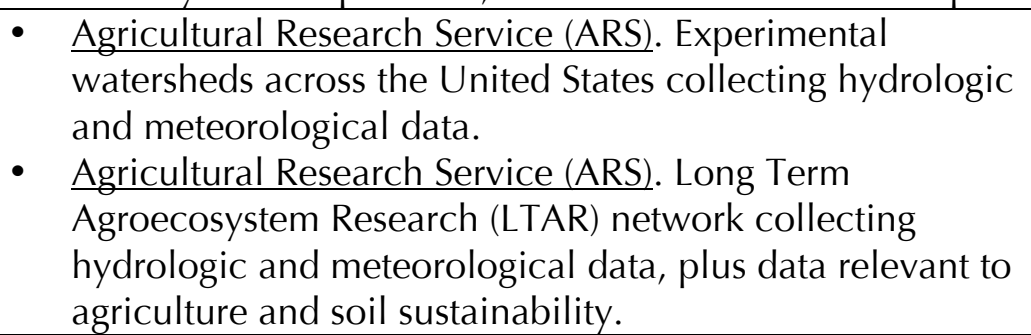 \\
\hline $\begin{array}{l}\text { National Science Foundation } \\
\text { (NSF) }\end{array}$ & 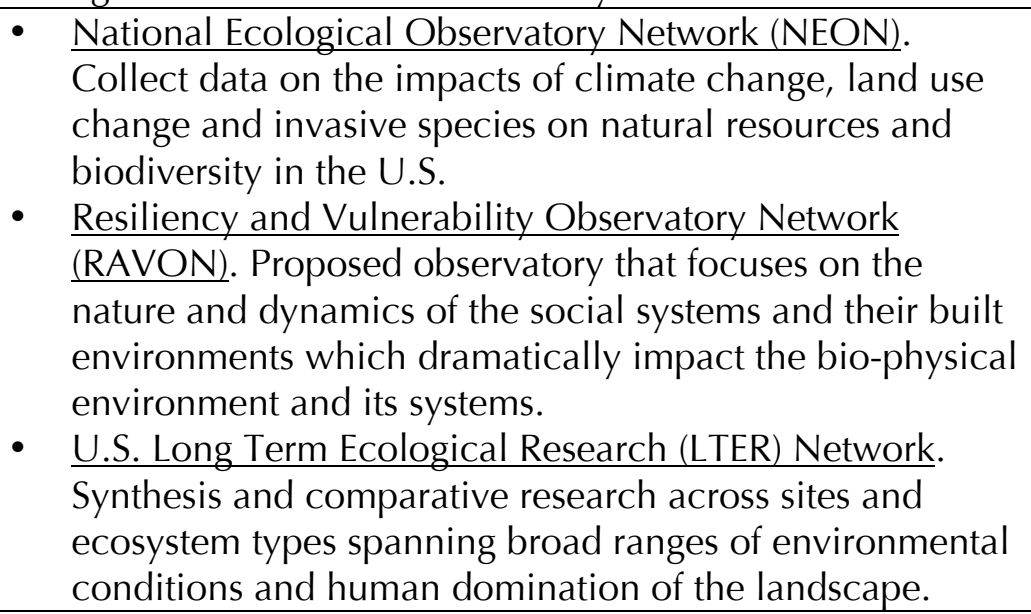 \\
\hline NASA & 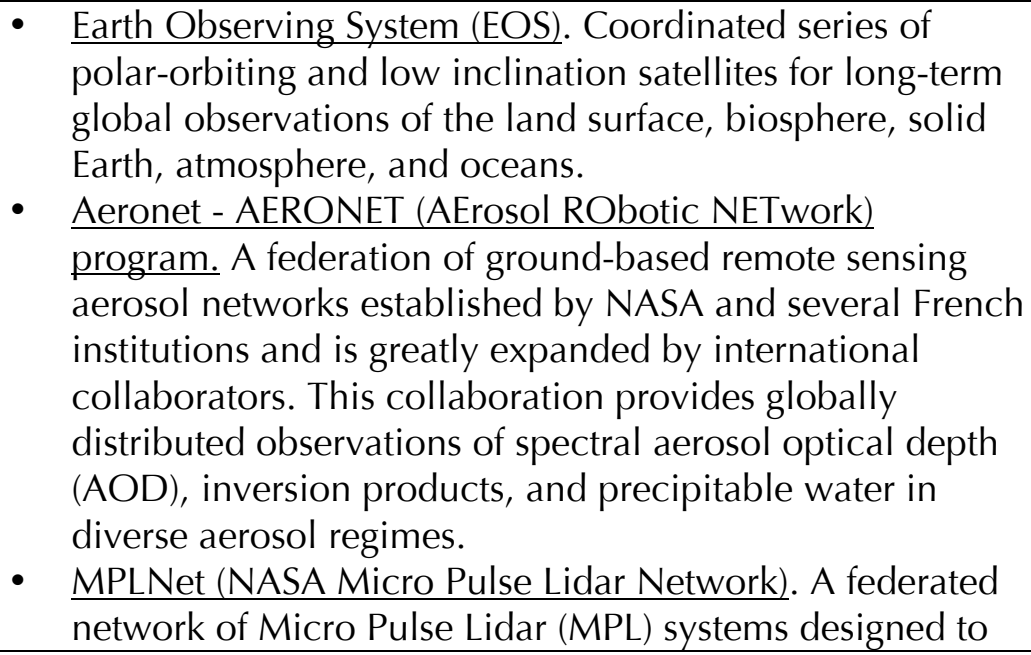 \\
\hline
\end{tabular}




\begin{tabular}{|c|c|}
\hline & 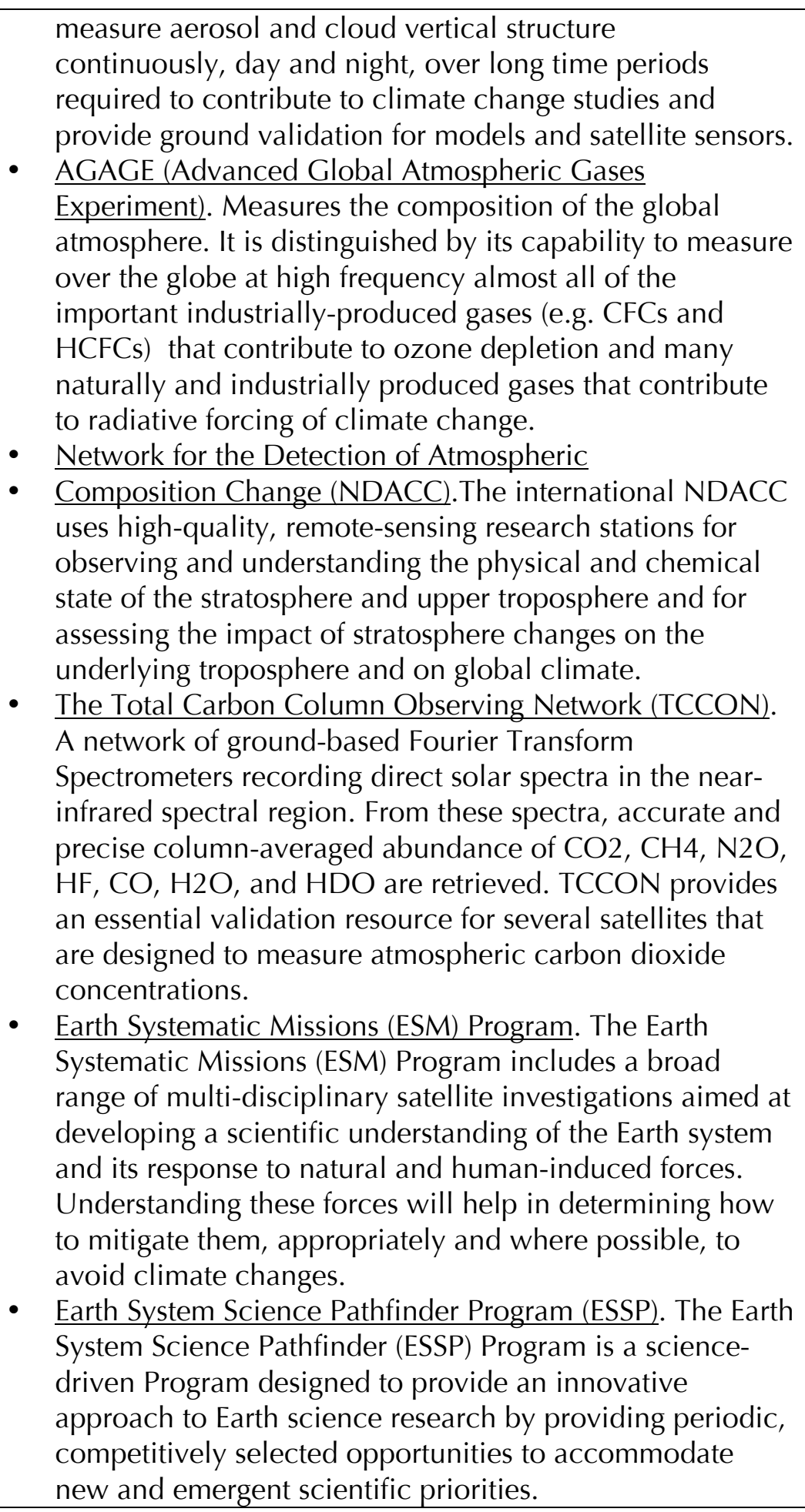 \\
\hline $\begin{array}{l}\text { Department of Health and } \\
\text { Human Services (HHS), } \\
\text { Centers for Disease Control } \\
\text { (CDC) }\end{array}$ & $\begin{array}{l}\text { - National Environmental Public Health Tracking Network } \\
\text { (Tracking Network). System of integrated health, } \\
\text { exposure, and hazard information and data from a variety } \\
\text { of national, state, and city sources. } \\
\text { - Global Health. Coordinates and manages the agency's } \\
\text { resources and expertise to address global challenges such }\end{array}$ \\
\hline
\end{tabular}




\begin{tabular}{|c|c|}
\hline & $\begin{array}{l}\text { as HIV/AIDS, malaria, emergency and refugee health, } \\
\text { non-communicable diseases, injuries, and more. }\end{array}$ \\
\hline Department of Energy (DOE) & $\begin{array}{l}\text { - U.S. Energy Information Administration (EIA). Collects, } \\
\text { analyzes, and disseminates independent and impartial } \\
\text { energy information to understand energy and its } \\
\text { interaction with the economy and the environment. }\end{array}$ \\
\hline $\begin{array}{l}\text { Department of Homeland } \\
\text { Security (DHS), Federal } \\
\text { Emergency Management } \\
\text { Agency (FEMA) }\end{array}$ & $\begin{array}{l}\text { - Mapping and Analysis Center (MAC). National level } \\
\text { Mapping using Geographic Information Systems (GIS) } \\
\text { including remote sensing data that indicates areas affected } \\
\text { by the disaster, such as include flooded, saturated, and/or } \\
\text { damaged areas, as derived from various imagery products. } \\
\text { - Map Services Center (MSC). Hydrologic and hydraulic } \\
\text { studies (that is, Flood Insurance Studies (FIS)) that identify } \\
\text { flood-prone areas and provide flood risk data that support } \\
\text { the spatial extent of Special Flood Hazard Areas (SFHAs) } \\
\text { and other thematic features related to flood risk } \\
\text { assessment. }\end{array}$ \\
\hline $\begin{array}{l}\text { Environmental Protection } \\
\text { Agency (EPA) }\end{array}$ & $\begin{array}{l}\text { Greenhouse Gas Data. Includes EPA's Inventory of U.S. } \\
\text { Greenhouse Gas Emissions and Sinks and Greenhouse } \\
\text { Gas Data Publication Tool. }\end{array}$ \\
\hline
\end{tabular}




\section{B. Examples of Federal Interagency Monitoring Networks and Observation Systems}

\begin{tabular}{|c|c|}
\hline Interagency Efforts & Programs that Directly Participate in the Activity \\
\hline $\begin{array}{l}\text { National Oceanic and } \\
\text { Atmospheric Administration } \\
\text { (NOAA)/NASA/Office of Naval } \\
\text { Research/National Science } \\
\text { Foundation/Arctic Research } \\
\text { Commission/U.S. Army Corps of } \\
\text { Engineers/Coast } \\
\text { Guard/USDA/Department of } \\
\text { Energy/Department of } \\
\text { Interior/Department of } \\
\text { State/Department of } \\
\text { Transportation/Environmental } \\
\text { Protection Agency/Food and } \\
\text { Drug } \\
\text { Administration/USGS/Marine } \\
\text { Mammal Commission/Bureau of } \\
\text { Ocean Energy Management, } \\
\text { Regulation, and } \\
\text { Enforcement/Office of the } \\
\text { Oceanographer and Navigator of } \\
\text { the Navy }\end{array}$ & $\begin{array}{l}\text { - Integrated Ocean Observing System (IOOS). Data and } \\
\text { information needed to collect, deliver, and use ocean } \\
\text { information. }\end{array}$ \\
\hline $\begin{array}{l}\text { National Park Service/National } \\
\text { Oceanic and Atmospheric } \\
\text { Administration } \\
\text { (NOAA)/NASA/NSF/Oak Ridge } \\
\text { National Laboratory/U.S. Fish } \\
\text { and Wildlife Service/USGS }\end{array}$ & $\begin{array}{l}\text { USA National Phenology Network (NPN). } \\
\text { Contemporary and historic multi-scale information on } \\
\text { organismal and land-surface phenology. }\end{array}$ \\
\hline $\begin{array}{l}\text { USDA/Department of } \\
\text { Commerce/Department of } \\
\text { Energy/Department of Homeland } \\
\text { Security/Department of } \\
\text { Interior/Department of } \\
\text { Transportation/U.S. Army Corps } \\
\text { of Engineers/Environmental } \\
\text { Protection Agency/Farm Credit } \\
\text { Administration/Federal Energy } \\
\text { Regulatory Commission/Internal } \\
\text { Revenue Service/International } \\
\text { Trade } \\
\text { Commission/NASA/NSF/Small } \\
\text { Business Administration }\end{array}$ & $\begin{array}{l}\text { - National Integrated Drought Information System } \\
\frac{\text { NIDIS. Integrated drought monitoring and forecasting }}{\text { system at federal, state, and local levels. }}\end{array}$ \\
\hline
\end{tabular}




\section{The Review Process for the Indicators Technical Input Report}

The Indicators Working Group decided to prepare a Technical Input Report at its first in-person meeting in Boulder, CO in November of 2011. An outline was prepared by the co-chairs, and discussed with the members of the working group through email and conference calls. A one-day writing meeting was held at the Joint Global Change Research Institute in January of 2012, at which time final revisions to the outline were made, and writing tasks begun by the Working Group members. The members of the Work Group also recruited scientists external to the Work Group to write sections on specific indicators or indicator systems. The first full draft was sent simultaneously to members of the Working Group and to outside reviewers on February 17, 2012, and comments were due by Friday, February 24th. Revisions were made largely by the co-chairs and staff to the Working Group, and a final version prepared for submission by Wednesday, February 29th.

External reviews were solicited from 34 experts in government agencies, state and local agencies, National Laboratories, and academia. Ten reviewers responded. Technical comments were considered and incorporated as appropriate either by section authors or by the Co-Chairs. Several reviewers pointed out the need for some structural changes in the report. The most important change was the addition of a section on a conceptual framework for the indicators, and deletion of descriptions about potential paths forward. The former change was made to reinforce the purpose of the paper to provide a conceptual framework and demonstrate that there is already a great deal of relevant work on indicators, but that major gaps remain. The latter change was made to reinforce that this technical input report was not meant to be a road-map to implementation. That road-map must be created, of course, but that is a future work product of the Indicators Working Group and not the goal of this report.

We thank the reviewers for their efforts to improve the technical input report. All interpretations and any remaining errors are the responsibility of the authors. 